\title{
Condicionalidad y deuda soberana: Un panorama general de sus implicancias en los derechos humanos
}

\author{
Conditionality and Sovereign Debt. An Overview \\ of Human Rights Implications
}

\author{
Tomas Stubbs ${ }^{1}$ \\ Royal Holloway/Universidad de Cambridge, \\ Reino Unido \\ Alexander Kentikelenis ${ }^{2}$ \\ Universidad de Oxford, Reino Unido \\ Universidad de Amsterdam, Holanda
}

Revista Derechos en Acción ISSN 2525-1678/ e-ISSN 2525-1686

Año 6/NNo 18 Verano 2020-2021 (21 diciembre a 20 marzo), 173-215

DOl: https://doi.org/10.24215/25251678e481

Resumen: Las Instituciones Financieras Internacionales (IFI) suelen condicionar la concesión de préstamos, subvenciones y alivio de la deuda a la aplicación de reformas políticas por parte del país receptor. Entre las medidas más comunes que se exigen a los gobiernos están la privatización de activos públicos, los recortes del gasto público (o "austeridad") y las reformas estructurales (como los cambios en las reformas del mercado laboral, la liberalización del comercio y la reforma legal). Estas denominadas "condicionalidades" otorgan a las IFI una influencia política sustancial sobre los gobiernos de todo el mundo, reduciendo así el espacio político nacional y socavando las agendas nacionales de

1 Senior Lecturer in International Relations, Royal Holloway, University of London; and Research Associate in Political Economy, University of Cambridge

2 Assistant Professor of Political Economy and Sociology, Bocconi University. La versión en inglés de este artículo fue publicada en Illias Bantekas and Cephas Lumina (eds.), Sovereign Debt and Human Rights (Oxford University Press, 2018). 
desarrollo. Estas medidas también tienen implicaciones para el disfrute de los derechos humanos. Este artículo ofrece una visión general de las políticas de las IFI, así como de su impacto en la capacidad de los gobiernos que las aplican para proporcionar los servicios públicos básicos necesarios para la realización de los derechos humanos, incluyendo la salud, el trabajo y los derechos civiles y políticos. El artículo comienza con un examen de los mandatos del FMl y del Banco Mundial. A continuación, analiza las prácticas de préstamo de ambas instituciones y revisa los debates existentes en torno a los efectos de las condicionalidades sobre los derechos humanos. Por último, el artículo ofrece sugerencias para reformar las prácticas de préstamo del FMI y del Banco Mundial, de manera que se garantice el respeto de los derechos humanos.

\begin{abstract}
International financial institutions (IFIs) typically condition the provision of loans, grants, and debt relief on the recipient country's implementation of policy reforms. Common measures that governments are required to implement include privatization of public assets, public spending cuts (or 'austerity'), and structural reforms (such as changes to labour market reforms, trade liberalisation, and legal reform). These so-called 'conditionalities' afford IFIs substantial policy influence on governments throughout the world, thereby reducing national policy space and undermining national development agendas. These measures also have implications for the enjoyment of human rights. This article provides an overview of IFI policies, as well as their impact on the ability of the implementing governments to provide basic public services necessary for the realisation of human rights, including health, labour, and civil and political rights. The article begins with an examination of the mandates of the IMF and World Bank. It then discusses the lending practices of the two institutions and reviews existing debates around the effects of conditionalities on human rights. Finally, the article offers suggestions for reform of IMF and World Bank lending practices in ways that ensure that they respect human rights.
\end{abstract}

\title{
I. Introducción
}

Las Instituciones Financieras Internacionales (IFI) suelen condicionar sus préstamos, donaciones y la reducción de deuda 
a la implementación de reformas en las políticas por parte del país receptor, enfocadas a tornar sostenible la situación fiscal y de deuda, mejorar la competitividad y acelerar el crecimiento económico. Las medidas más típicas que los gobiernos deben implementar incluyen la privatización de activos públicos, los recortes del gasto público —o medidas de ajuste- y reformas estructurales (tales como la desregulación del mercado laboral, la liberalización del comercio y una reforma legal). Esta práctica de imponer "condicionalidades" provee a las IFIs de una influencia política sustancial en los Estados en todo el mundo, reduciendo de esta forma el espacio para las políticas nacionales, socavando las agendas propias de desarrollo. ${ }^{3}$ En este sentido, las medidas citadas también tienen implicaciones para el goce de los derechos humanos.

En este artículo se proporciona un panorama general de estas políticas, así como el impacto que conlleva su adopción por parte de los gobiernos a la hora de proporcionar servicios básicos, necesarios para la realización de los derechos humanos, incluyendo salud, trabajo, derechos civiles y políticos, etc. El artículo comienza con un examen de los mandatos del Fondo Monetario Internacional (FMI) y el Banco Mundial. Posteriormente analiza las prácticas crediticias de ambas instituciones y trata los debates existentes sobre los efectos de la condicionalidad en los derechos humanos. Finalmente, se ofrecen sugerencias para la reforma de las prácticas creditorias por parte del FMI y el Banco Mundial, de manera tal que se garantice el respeto por los derechos humanos.

\section{Una breve historia del FMI y el Banco Mundial}

Funcionando como último recurso en materia de préstamos para aquellos países que experimentan niveles insostenibles

\footnotetext{
3 Alexander Kentikelenis, Thomas Stubbs, Lawrence King, "IMF Conditionality and Development Policy Space, 1985-2014", 4 Review of International Political Economy, 2016, vol. 23, 543.
} 
de deuda soberana, el FMI y el Banco Mundial se encuentran entre las IFIs más influyentes. ${ }^{4}$ Ambas organizaciones cuentan con una gama similar de herramientas para persuadir a los gobiernos de que adopten reformas, siendo la más conocida de ellas la condicionalidad, entendiendo a esta como la práctica de exigir reformas políticas a cambio de acceder a los recursos financieros brindados por las IFIs. En los contratos de préstamos condicionales con las IFIs, las reformas políticas se describen en documentos que especifican los cronogramas para su puesta en marcha y son evaluadas de forma regular. La no implementación por parte de los Estados puede resultar en demoras a la hora de desembolsar los préstamos y, en última instancia, la suspensión total de los mismos.

Los orígenes de estas organizaciones se remontan a la conferencia de Bretton Woods en julio de 1944, la cual sentó las bases del orden económico posterior a la Segunda Guerra Mundial. ${ }^{5}$ En respuesta a las demandas por un sistema global de gobernanza financiera y una mayor cooperación económica, se crearon poco después (en 1945) el FMI y el Banco Internacional de Reconstrucción y Desarrollo (BIRD, más tarde conocido simplemente como Banco Mundial).

Ambas organizaciones se han apartado de su mandato original establecido en Bretton Woods. El papel del FMI era inicialmente supervisar los tipos de cambio de los Estados miembro y poner a disposición de estos últimos recursos financieros en el caso de que enfrentaran problemas en su balanza de pagos. ${ }^{6}$ Tras la transformación de este sistema a uno de tipos de cambio

\footnotetext{
4 Alexander Kentikelenis, Leonard Seabrooke, "The Politics of World Polity: Script-Writing in International Organizations", 5 American Sociological Review, 2017, vol. 82, 1065; Ngaire Woods, The Globalizers: The IMF, the World Bank, and Their Borrowers, (Cornell University Press, 2006).

5 Sarah Babb, Alexander Kentikelenis, "International Financial Institutions as Agents of Neoliberalism" en Damien Cahill, Melinda Cooper, Martjin Konings, and David Primrose (eds.), The Sage Handbook of Neoliberalism, (Sage, 2018), 16.
}

6 FMI, Articles of Agreement (2016). 
flotantes en 1973, solo sobrevivió el segundo aspecto - y el más controvertido- del mandato del FMI. Por su parte, el Banco Mundial se estableció para proporcionar capital de inversión para la reconstrucción y el desarrollo económico de posguerra. Inicialmente se especializó en préstamos a países desarrollados para proyectos de infraestructura, como puertos, ferrocarriles y represas hidroeléctricas. Sin embargo, en respuesta a la necesidad de los países en desarrollo de una mayor financiación, los líderes mundiales establecieron en 1960 una organización adicional dentro del Banco Mundial, la Asociación Internacional de Fomento (AIF). Esto transformó al Banco en una organización más centrada en el desarrollo, ampliando su mandato con el fin de abarcar la erradicación de la pobreza. ${ }^{7}$

Al cumplir con estas funciones revisadas, las dos organizaciones se involucraron en la promoción de reformas tendientes a la liberalización del mercado como parte de sus operaciones crediticias. ${ }^{8}$ En los años setenta y ochenta, el FMI introdujo una serie de programas de préstamos dirigidos al cambio estructural, tales como el programa de facilidades extendidas y el de ajuste estructural. ${ }^{9}$ Antes de esto, las condiciones vinculadas a los préstamos del FMI se limitaban en gran medida a una serie de objetivos básicos cuantificables, como topes al gasto público y activos domésticos; en cambio, estos nuevos programas incorporaron detalladas reformas microeconómicas que abarcan una amplia gama de políticas. Por su parte, el Banco Mundial continuó su tradición de proporcionar préstamos para "proyectos", como por ejemplo para construir carreteras o

7 Devesh Kapur, John P. Lewis, Richard Webb, The World Bank: Its First Half Century, vol. 1: History, (Brookings Institution Press, 1997).

8 Sarah Babb, Behind the Development Banks: Washington Politics, World Poverty, and the Wealth of Nations (University of Chicago Press, 2009).

9 Sarah Babb, Ariel Buira, "Mission Creep, Mission Push and Discretion: The Case of IMF Conditionality" in Ariel Buira (ed.), The IMF and World Bank at Sixty (Anthem Press, 2005), 59; James Pfeifer, Rachel Chapman, "Anthropological Perspectives on Structural Adjustment and Public Health", Annual Review of Anthropology, 2010, vol. 39, 149. 
escuelas, pero también introdujo en 1980 un préstamo propio vinculado a "programas", el Préstamo de Ajuste Estructural. ${ }^{10}$ A medida que avanzaba la década los ochenta, el Banco Mundial dedicó mayor proporción de sus recursos para estos préstamos vinculados a programas en vez de para proyectos de desarrollo. Por su parte, el FMI se convirtió, a todos los efectos, en un organismo de desarrollo que colaboró con el Banco Mundial. ${ }^{11}$

En un contexto de crisis de deuda, los programas de ajuste estructural se volvieron omnipresentes en la década de los ochenta, logrando notoriedad por su requisito de que los países de ingresos bajos y medios implementaran políticas de libre mercado. ${ }^{12}$ De hecho, el término "ajuste estructural" se convirtió en la abreviatura de una amplia gama de reformas diseñadas para promover revisión integral y duradera de las políticas públicas del país prestatario. ${ }^{13}$ Estas políticas se ordenaron en torno a cuatro pilares: estabilización, liberalización, desregulación y privatización. ${ }^{14}$ La estabilización, o simplemente el "ajuste", se refiere a las medidas diseñadas para reducir el déficit fiscal y la oferta monetaria, destinadas a controlar la inflación, estabilizar el valor de las monedas y liberar recursos para pagar la deuda externa. La liberalización implica la eliminación de barreras al comercio y la circulación de capitales para facilitar el acceso a mercados y promover la inversión extranjera directa. La desregulación implica la derogación de las reglas, regulaciones, controles y contrapesos gubernamentales que regulan la actividad económica, orientadas a abolir las ineficiencias percibidas en el funcionamiento del sector privado. Finalmente, la privatización ocasiona la

\footnotetext{
10 Babb y Kentikelenis (nota 5).

11 Babb (nota 8); Babb y Buira (nota 9).

12 Babb y Kentikelenis (nota 5).

13 Pfeifer y Chapman (nota 9)

14 Lawrence H Summers, Lant H Pritchett, "The Structural-Adjustment Debate" , 2 American Economic Review, 1993, vol. 83, 383.
} 
venta empresas y recursos naturales de propiedad estatal al sector privado, con el objetivo de mejorar la gestión económica de estas industrias.

Para ambos organismos, la práctica de las condicionalidades se convirtió en una característica destacada de su modus operandi $i^{15} \mathrm{y}$, en la década de los noventa, era un vehículo básico para implementar la transición al capitalismo en países poscomunistas. Para asegurar el cumplimiento de estas prescripciones, no solo se recurrió a la amenaza de suspender los préstamos a los gobiernos receptores, sino que también fue alentado a través de relaciones más estrechas entre el FMI, el Banco Mundial, varios bancos regionales de desarrollo y acreedores privados. ${ }^{16}$ En particular, las diversas agencias armonizaron sus condiciones, y las sostuvieron entre sí, al tiempo que la presencia de programas de ajuste estructural pasaron a servir como un "sello de aprobación" que podría catalizar ayuda bilateral adicional de los gobiernos donantes, incluida la morigeración de deuda, así como atraer flujos financieros de capital privado internacional. ${ }^{17}$ El Banco Mundial y los bancos regionales de desarrollo consolidaron su influencia política a través de una mayor selectividad en la concesión de préstamos para proyectos a países que cumplían con estas políticas. ${ }^{18}$

El FMI y el Banco Mundial fueron ampliamente criticados en los siguientes años, especialmente después del manejo que hicieron de las crisis financieras en México, Asia Oriental, Rusia

15 John Williamson, "What Washington Means by Policy Reform", en John Williamson (ed.), Latin American Adjustment: How Much Has Happened? (Institute for International Economics, 1990), 7.

16 Babb (nota 8).

17 Graham Bird, Dane Rowlands, "Do IMF Programmes Have a Catalytic Efect on Other International Capital Flows?" 3 Oxford Development Studies, 2002, vol. 30, 229; Tomas Stubbs, Alexander Kentikelenis, Lawrence King, "Catalyzing Aid? The IMF and Donor Behavior in Aid Allocation" World Development, 2016, vol. 78, 511.

18 David Dollar, Victoria Levin, "The Increasing Selectivity of Foreign Aid, 1984-2003", 12 World Development, 2006, vol. 34, 2034. 
y Argentina. ${ }^{19}$ Ambos organismos prometieron que las dolorosas medidas de austeridad se justificarían a largo plazo por un crecimiento económico sostenido. Sin embargo, el crecimiento económico no se materializó, ${ }^{20}$ mientras que abundaron implicaciones negativas para el goce de los derechos humanos (véase sección 4). Frente a esta evidencia desconcertante, la opinión de las organizaciones era que los programas de ajuste estructural no habían prestado suficiente atención a las instituciones que permiten el funcionamiento de los mercados, tales como las leyes y los sistemas judiciales, pero que el ímpetu subyacente de liberalización del mercado fue esencialmente correcto. ${ }^{21} \mathrm{~A}$ principios de la década de 2000 , y en respuesta a las críticas generalizadas, el FMI y el Banco Mundial se comprometieron a fortalecer la orientación de sus programas en favor de las personas pobres, permitiendo un diseño flexible de políticas. ${ }^{22}$

En 2009, tras el inicio de la crisis de la deuda soberana en Europa, los programas de ajuste estructural del FMI, en colaboración con instituciones de la Unión Europea, se extendieron a las economías europeas avanzadas de Grecia, Islandia, Irlanda, Portugal y Chipre. Estos programas fueron similares a los propugnados por el FMI y el Banco Mundial en países de ingresos bajos y medianos en la medida en que estos estaban bajo condicionalildades de una amplia liberalización del mercado. ${ }^{23}$

19 Sarah Babb, Bruce Carruthers, "Conditionality: Forms, Function, and History", Annual Review of Law and Social Science, 2008, vol. 4, 13; Joseph Stiglitz, Globalization and Its Discontents (WW Norton, 2002).

20 Dani Rodrik, One Economics, Many Recipies: Globalization, Institutions, and Economic Growth (Princeton University Press, 2007).

21 Babb y Kentikelenis (nota 5).

22 IMF, Creating Policy Space — Responsive Design and Streamlined Conditionality in Recent Low-Income Country Programs (IMF 2009); World Bank, 2009 Development Policy Lending Retrospective: Flexibility, Customization, and Results (IMF 2009).

23 Scott Greer, "Structural Adjustment Comes to Europe: Lessons for the Eurozone from the Conditionality Debates", 1 Global Social Policy, 2014, vol. 14, 51; Alexander Kentikelenis, "Structural Adjustment and Health: A Conceptual Framework and Evidence on Pathways", 187 Social Science \& Medicine, 2017, 296. 


\section{La evolución de la condicionalidad}

De manera sistemática, en los programas de ajuste estructural del FMI y del Banco Mundial se han utilizado las condicionalidades como un mecanismo de cumplimiento, así como también políticas fuertemente orientadas al libre mercado. ${ }^{24} \mathrm{Sin}$ embargo, las experiencias de condicionalidades también divergen de manera importante a través del tiempo y el espacio. Investigamos la evolución de las condicionalidades utilizando una base de datos de las reformas de políticas públicas exigidas por el FMI para el período 1980 a $2014 .^{25}$ Nos centramos en el FMI porque no se dispone de datos conmensurables para las condicionalidades del Banco Mundial. En cualquier caso, el FMI ha sido la principal organización en establecer los parámetros de espacio de política para sus prestatarios a lo largo de este período. ${ }^{26}$ Inicialmente, informamos sobre el número de condiciones aplicables. Aunque reveladora, esta medida resulta un indicador imperfecto para mostrar la carga de condicionalidades, porque no nos dice nada sobre la dificultad de implementar cualquier condición particular. Por ejemplo, una condición que estipula la privatización de una empresa de propiedad estatal es cualitativamente distinta de una que introduce un impuesto al valor agregado. Sin embargo, investigaciones previas muestran que el número de condiciones es una medida indirecta apropiada para conocer el nivel de intrusión de la condicionalidad ${ }^{27}$

24 Babb y Carruthers (nota 19); Greer (nota 23); Kentikelenis et al. (nota 3); Pfeifer y Chapman (nota 9).

25 Kentikelenis et al.(nota 3).

26 Nitsan Chorev, Sarah Babb, "The Crisis of Neoliberalism and the Future of International Institutions: A Comparison of the IMF and the WTO", 5 Teory and Society, 2009, vol. 38, 459.

27 Teri Caraway, Stephanie Rickard, Mark Anner, "International Negotiations and Domestic Politics: The Case of IMF Labor Market Conditionality", 1 International Organization, 2012, vol. 66, 27; Mark Copelovitch, "Master or Servant? Common Agency and the Political Economy of IMF Lending", 1 International Studies Quarterly, 2010, vol. 54, 49; Axel Dreher, Jan-Egbert Sturm, James Vreeland, "Politics and IMF Conditionality", 1 Journal of Confict Resolution, 2015, vol. 59, 120; Terrence Chapman et al., "Mixed Signals: IMF Lending and 


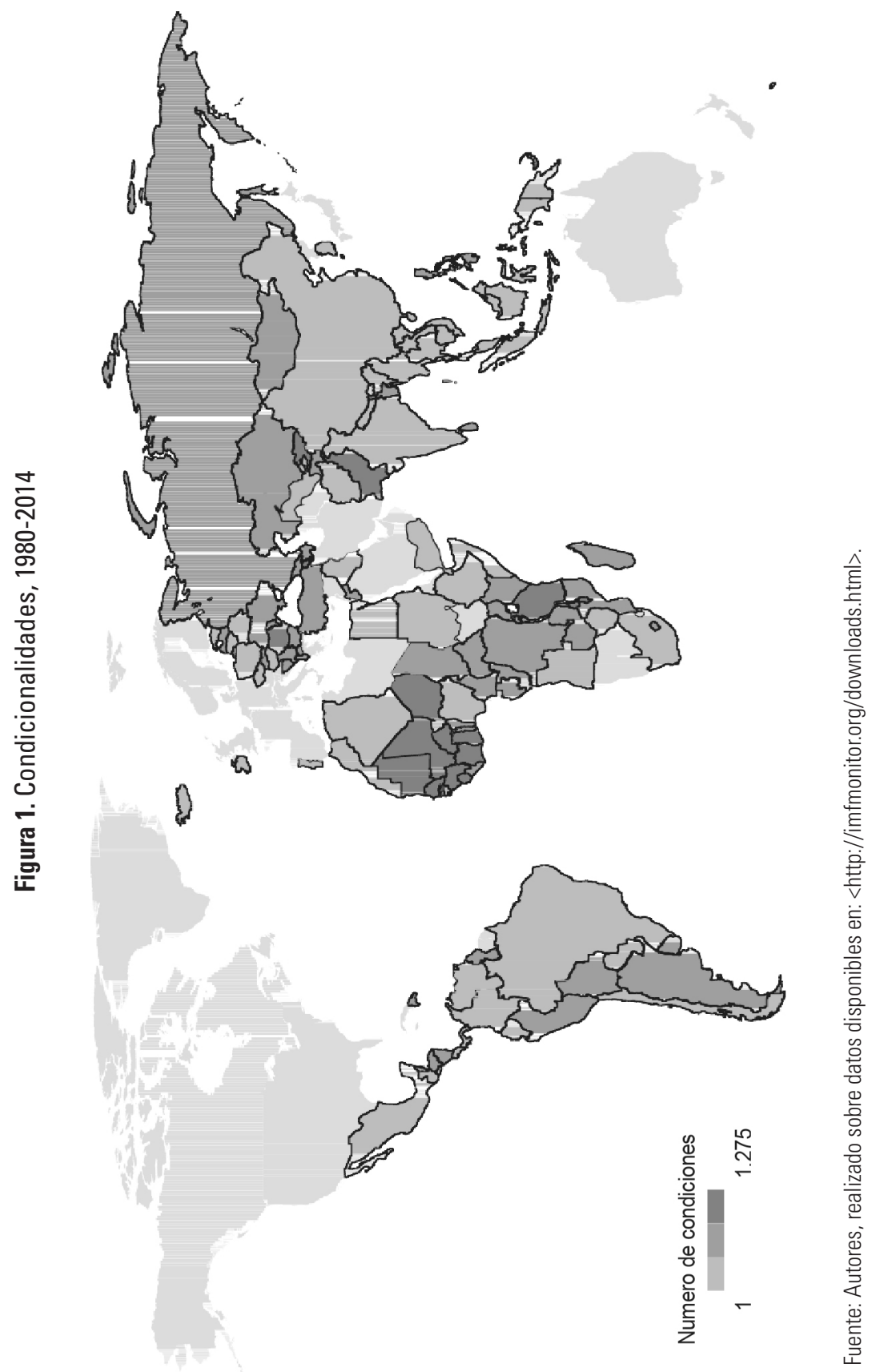


En la Figura 1 mapeamos el número total de condiciones aplicables en todos los préstamos del FMI para cada país entre 1980 y 2014. Allí se muestra cómo las experiencias de los países con respecto a las condicionalidades del FMI son muy divergentes. Varios Estados de la región de África occidental, incluida Guinea, Nigeria, Ghana, Costa de Marfil, Burkina Faso, Malí, Mauritania, Senegal y Sierra Leona, así como Armenia, Rumania, Pakistán, Tanzania y Kirguistán, exhiben una pesada carga de condicionalidades. Todos estos países contrajeron repetidamente préstamos que tenían un alto grado de condicionalidad. Rumania, por ejemplo, tenía programas del FMI para veintiséis de los treinta y cinco años cubiertos, con un total de 1271 condiciones, la mayor cantidad de todos los países. Otros países solo tuvieron breves encuentros con el FMI, que también se refleja en una condicionalidad relativamente limitada. Por ejemplo, Sudáfrica solo tuvo un Acuerdo Stand By de un año, con once condiciones adjuntas, vigente entre 1982 y 1983. Laos mantuvo 389 condiciones, que representa el número mediano de condiciones entre países que tuvieron al menos una. La mayoría de las naciones avanzadas no experimentaron ninguna condición durante el período cubierto porque no tomaron prestado del FMI, - aunque Chipre, Grecia, Islandia, Irlanda y Portugal constituyen excepciones notables.

El Cuadro 1 indica cómo ha evolucionado la condicionalidad del FMI entre 1980 y 2014. La media de las condiciones en los programas del FMI aumentó gradualmente de doce por año - a principios de la década de 1980 — hasta alrededor de cuarenta y dos en 1996, nivel en el que permaneció hasta 2007. Durante este período de alta condicionalidad, varios países de Europa del Este y Asia Central se destacan como valores atípicos altos, alcanzando un máximo de más de 140 condiciones para Rusia

Capital Markets", 2 British Journal of Political Science, 2017, vol. 47, 329; Tomas Stubbs et al., "The Impact of IMF Conditionality on Government Health Expenditure: A Cross-National Analysis of 16 West African Nations", 174 Social Science \& Medicine, 2017, 220. 
en 1998 y Ucrania en 1999. Una disminución abrupta en el número medio de condiciones aplicables puede observarse en las secuelas de la crisis financiera mundial, cayendo alrededor de treinta y tres condiciones por año. Aun así, se mantuvo considerablemente más alto que en los años ochenta y principios de los noventa. Desde 2008, Camerún, Moldova, Costa de Marfil, Ghana, Haití, Grecia, Afganistán, Bosnia, Bangladesh, Ucrania y Jamaica han experimentado una pesada carga de condicionalidad, teniendo todos sesenta o más condiciones al menos una vez. En 2014, el número mediano de condiciones aumentó drásticamente a cuarenta y cuatro, siendo la tercera cifra más alta registrada (después de cuarenta y siete en 2004 y cuarenta y cinco en 2003).

Cuadro 1. Estadísticas descriptivas sobre la condicionalidad

\begin{tabular}{|r|r|r|r|l|}
\hline & Media & Mediana & Programas & \multicolumn{1}{|c|}{ Mayor condicionalidad en... } \\
\hline 1980 & 12,1 & 12 & 34 & $\begin{array}{l}\text { Bolivia (28 condiciones), Turquía (25), } \\
\text { Rep. Dem. Del Congo (21) }\end{array}$ \\
\hline 1981 & 11,7 & 12 & 42 & $\begin{array}{l}\text { Madagascar (27), Turquía (22), } \\
\text { Jamaica (21) }\end{array}$ \\
\hline 1982 & 11,9 & 12 & 37 & $\begin{array}{l}\text { Jamaica (27), Uganda (23), Costa de } \\
\text { Marfil (20) }\end{array}$ \\
\hline 1983 & 14,8 & 15,5 & 54 & $\begin{array}{l}\text { República Dominicana (33), Argentina } \\
\text { (30), Turquía \& Jamaica (28) }\end{array}$ \\
\hline 1984 & 18,7 & 18,5 & 42 & $\begin{array}{l}\text { Jamaica (50), Brasil (49), Costa de } \\
\text { Marfil (32) }\end{array}$ \\
\hline 1985 & 20,9 & 23 & 36 & Jamaica (46), Argentina (36), Ghana (32) \\
\hline 1986 & 20,9 & 17 & 43 & $\begin{array}{l}\text { Marruecos (65), Zambia (63), Rep. Dem. } \\
\text { Del Congo. (40) }\end{array}$ \\
\hline 1987 & 27,3 & 28 & 35 & $\begin{array}{l}\text { Tanzania (49), Niger (42), Gabón, } \\
\text { Senegal \& Túnez (40) }\end{array}$ \\
\hline 1988 & 25,3 & 24 & 46 & Tanzania (57), Togo (56), Túnez (49) \\
\hline 1989 & 28,8 & 30 & 50 & Pakistan (87), Nepal (56), Túnez (52) \\
\hline 1990 & 26,7 & 25,5 & 50 & Pakistan (61), Tanzania (59), Gabón (54) \\
\hline 1991 & 26,9 & 25 & 53 & Túnez(52), Ruanda y Senegal (46) \\
\hline
\end{tabular}




\begin{tabular}{|c|c|c|c|c|}
\hline & Media & Mediana & Programas & Mayor condicionalidad en... \\
\hline 1992 & 29,7 & 29 & 54 & India (62), Gabón (56), Pakistan (54) \\
\hline 1993 & 28,4 & 28 & 48 & $\begin{array}{l}\text { Mauritania (73), Egipto (56), Burkina } \\
\text { Faso (53) }\end{array}$ \\
\hline 1994 & 36,5 & 36,5 & 60 & $\begin{array}{l}\text { Mauritania (76), Kirguistán (70), } \\
\text { Albania (66) }\end{array}$ \\
\hline 1995 & 36,3 & 37 & 67 & $\begin{array}{l}\text { Mauritania (88), Ucrania (78), } \\
\text { Armenia (72) }\end{array}$ \\
\hline 1996 & 43,9 & 42,5 & 68 & Azerbaiyán (93), Rusia (87), Georgia (70) \\
\hline 1997 & 42,9 & 42 & 60 & $\begin{array}{l}\text { Kazajistán (99), Bulgaria (89), } \\
\text { Azerbaiyán (88) }\end{array}$ \\
\hline 1998 & 43,2 & 43,5 & 60 & Rusia (143), Ucrania (103), Indonesia (77) \\
\hline 1999 & 44,3 & 41 & 62 & $\begin{array}{l}\text { Ucrania (148), Bulgaria (99), } \\
\text { Moldavia (89) }\end{array}$ \\
\hline 2000 & 40,8 & 42,5 & 64 & $\begin{array}{l}\text { Kirguistán (97), Bulgaria (87), } \\
\text { Rumania (79) }\end{array}$ \\
\hline 2001 & 41,8 & 40 & 66 & $\begin{array}{l}\text { Pakistan (105), Ucrania, Ruanda \& } \\
\text { Armenia (72) }\end{array}$ \\
\hline 2002 & 43,1 & 40,5 & 58 & $\begin{array}{l}\text { Rumania (114), Pakistan (98), } \\
\text { Turquía (86) }\end{array}$ \\
\hline 2003 & 45,3 & 45 & 57 & $\begin{array}{l}\text { Romania (114), Pakistan (87), } \\
\text { Macedonia (80) }\end{array}$ \\
\hline 2004 & 43,5 & 47 & 57 & $\begin{array}{l}\text { Rumania (126), Serbia (87), } \\
\text { Nicaragua (74) }\end{array}$ \\
\hline 2005 & 44,5 & 43 & 47 & $\begin{array}{l}\text { Serbia (122), Rumania (100), } \\
\text { Senegal (83) }\end{array}$ \\
\hline 2006 & 39,7 & 41 & 43 & $\begin{array}{l}\text { Camerún (79), Macedonia \& República } \\
\text { del Congo (65) }\end{array}$ \\
\hline 2007 & 40,4 & 40 & 37 & $\begin{array}{l}\text { Camerún (84), República Dominicana } \\
\text { (77), Macedonia (67) }\end{array}$ \\
\hline 2008 & 30,4 & 33 & 46 & Camerún (75), Moldavia (62), Haití (60) \\
\hline 2009 & 31,8 & 33 & 53 & $\begin{array}{l}\text { Costa de Marfil (70), Afganistán (53), } \\
\text { República Centroafricana (51) }\end{array}$ \\
\hline 2010 & 32,9 & 34 & 60 & $\begin{array}{l}\text { Ghana y Costa de Marfil (60), } \\
\text { Tayikistán (58) }\end{array}$ \\
\hline 2011 & 31,7 & 32 & 50 & Haití (60), Tayikistán (58), Ghana (54) \\
\hline
\end{tabular}




\begin{tabular}{|c|c|r|r|l|}
\hline & Media & Mediana & Programas & \multicolumn{1}{|c|}{ Mayor condicionalidad en... } \\
\hline 2012 & 32,5 & 35 & 45 & $\begin{array}{l}\text { Grecia (62), Afganistán (60), Costa de } \\
\text { Marfil (59) }\end{array}$ \\
\hline 2013 & 33,7 & 34,5 & 40 & $\begin{array}{l}\text { Bosnia-Herzegovina (85), Bangladesh } \\
\text { (69), Costa de Marfil (68) }\end{array}$ \\
\hline 2014 & 38,7 & 44 & 35 & $\begin{array}{l}\text { Bosnia-Herzegovina (92), Ucrania (64), } \\
\text { Jamaica (63) }\end{array}$ \\
\hline Total & 33,2 & 32 & & $\begin{array}{l}\text { Rumania (1271), Pakistán (1166), } \\
\text { Mauritania (1080) }\end{array}$ \\
\hline
\end{tabular}

Fuente: Autores, realizado sobre datos disponibles en: <http://imfmonitor.org/downloads.html>.

Figura 2. Condicionalidad en Europa y Asia Central, 1980-2014

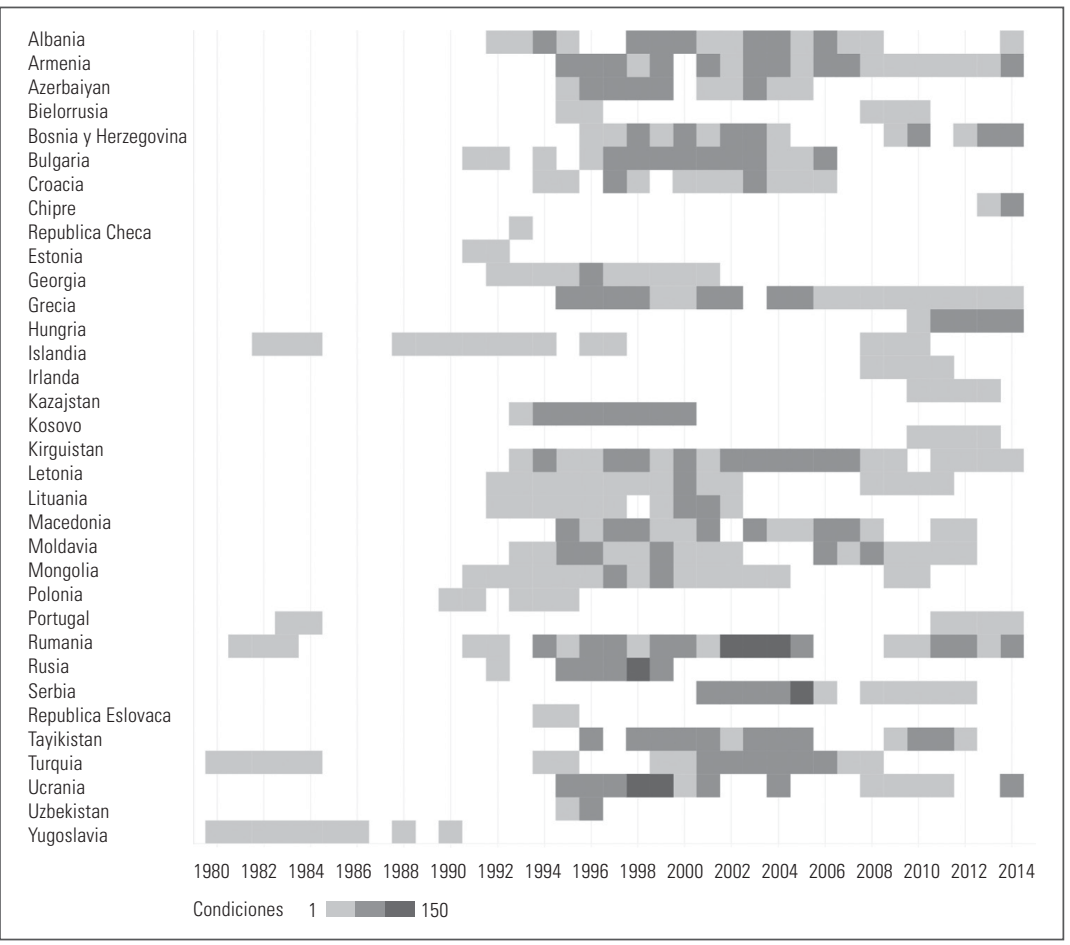

Fuente: Autores, Realizado sobre datos disponibles en: <http://imfmonitor.org/downloads.html>. 
La Figura 2 presenta información más detallada sobre los países de Europa y Asia Central, donde el FMI estuvo muy involucrado durante la transición poscomunista al capitalismo. El mapa de calor muestra la carga de la condicionalidad aplicable por país y año. Por ejemplo, Rumania tuvo numerosos programas con cargas pesadas, particularmente entre 1994 y 2005, mientras que Rusia tenía pocos programas pero una alta carga de condicionalidad en cada uno durante el período 1995-1999. De los países europeos de altos ingresos que recibieron préstamos del FMI en años recientes, Grecia se destaca por tener un mayor número de condiciones aplicables, más de cincuenta por año entre 2011 y 2014. También hay evidencia de reincidencia del FMI en la región, con Armenia, Georgia y la República Kirguisa en programas consecutivos y prácticamente ininterrumpidos desde aproximadamente 1995.

Figura 3. Condicionalidad en África Occidental, 1980-2014

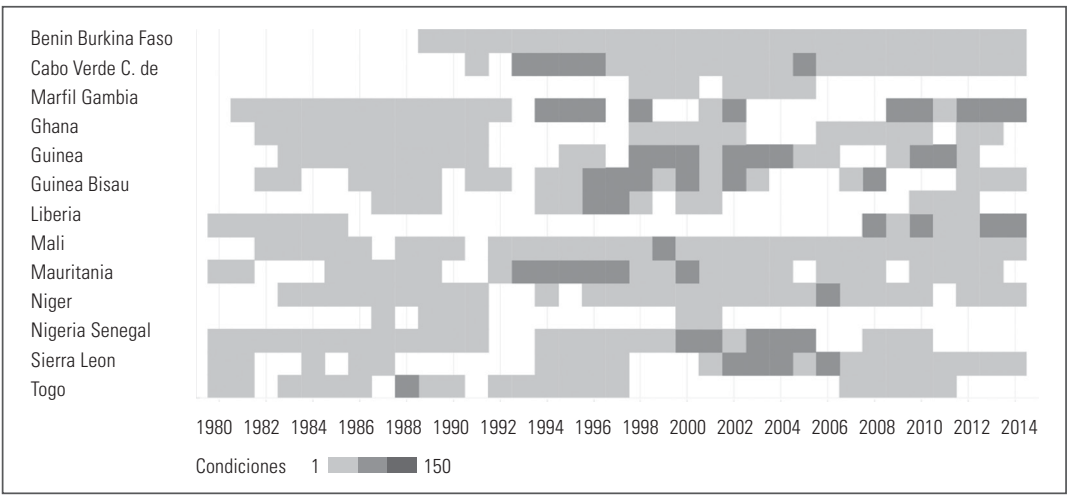

Fuente: Autores, sobre datos disponibles en: <http://imfmonitor.org/downloads.html>.

En la Figura 3 ofrecemos la misma información para los dieciséis países de África occidental, otra región con una fuerte participación del FMI. Allí puede notarse que la reincidencia a dicha institución es una característica destacada en la región. Con excepción de Cabo Verde, Guinea-Bissau, Liberia y Nigeria, cada uno de estos países estuvo la mayor parte del período 
1980-2014 bajo los programas del FMI, lo que subraya la medida en que dicha institución ha influido en la trayectoria de desarrollo de la región. Mauritania, que tiene la tercera carga más alta de condicionalidad de todos los países, estuvo sujeta a amplias condicionalidades del FMI desde 1993 hasta 1997, y nuevamente en 2000, cuando se indujo al país a implementar setenta y tres condiciones del FMI. Más recientemente, Costa de Marfil tuvo que implementar más de cincuenta condiciones durante cinco de los seis años transcurridos desde 2009.

Si bien las tendencias en los números totales de las condiciones son sugerentes, para evaluar la condicionalidad del FMI se requiere explorar también su distribución entre diferentes áreas de políticas públicas - el llamado alcance de la condicionalidad- ${ }^{28}$ En el Cuadro 2 presentamos las áreas de política pública de las condiciones del FMI para el período 1980-2014, clasificándolas en categorías mutuamente excluyentes. Siguiendo convenciones del campo de investigación, estas se separan en áreas de políticas principales (core) y no principales. ${ }^{29}$ Las áreas políticas principales incluyen problemas de deuda externa, del sector financiero, de política monetaria y cuestiones de bancos centrales, de problemas fiscales, ingresos e impuestos; y del sector externo (cuestiones comerciales y cambiarias). ${ }^{30}$ En conjunto, estas áreas principales representan casi el $87 \%$ del número total de condiciones incluidas en los programas del FMI.

28 Randall Stone, "The Scope of IMF Conditionality", 4 International Organization, 2008, vol. 62, 589; Graham Bird, "Reforming IMF Conditionality: From 'Streamlining' to 'Major Overhaul'", 3 World Economics, 2009, vol. 10, 81.

29 IEO, Structural Conditionality in IMF-Supported Programs: Background Documents (2007); Kentikelenis et al. (nota 17).

30 Stubbs, Kentikelenis y King et al. (nota 17). 
Cuadro 2. Categorización de áreas políticas

\begin{tabular}{|c|c|c|}
\hline & Descripcion de areas politicas & $\begin{array}{l}\text { Número de } \\
\text { condiciones }\end{array}$ \\
\hline \multirow{5}{*}{$\begin{array}{l}\text { Políticas } \\
\text { en zonas } \\
\text { centrales }\end{array}$} & $\begin{array}{l}\text { Problemas de deuda externa } \\
\text { Gestion de la deuda y atrasos externos }\end{array}$ & 16,571 \\
\hline & $\begin{array}{l}\text { Problemas del sector financiero, políticas } \\
\text { monetarias y Bancos Centrales } \\
\text { Regulación de instituciones financieras, } \\
\text { privatización de empresas publicas financieras, } \\
\text { letras del tesoro, tasas de interés, regulación del } \\
\text { Banco Central, oferta monetaria y credito interno }\end{array}$ & 15,229 \\
\hline & $\begin{array}{l}\text { Problemas fiscales, ingresos e impuestos } \\
\text { Administracion de gastos, transparencia fiscal, } \\
\text { auditorias, elaboracion de presupuestos, atrasos } \\
\text { internos y balance fiscal, administracion de } \\
\text { aduanas, politica tributaria, administracion } \\
\text { tributaria y auditorias de empresas privadas }\end{array}$ & 13,952 \\
\hline & $\begin{array}{l}\text { Sector externo (comercio y sistema cambiario) } \\
\text { Reservas extranjeras, liberalización del comercio, } \\
\text { política cambiaria, liberalización de la cuenta de } \\
\text { capital e inversion extranjera directa }\end{array}$ & 5,142 \\
\hline & $\begin{array}{l}\text { Privatización de empresas públicas, reformas y } \\
\text { puesta en valor } \\
\text { Privatización de empresas públicas no financieras } \\
\text { (incluidos procedimientos de liquidación y } \\
\text { quiebra), reestructuración de empresas públicas } \\
\text { estatales, subsidios, liberalización de precios, } \\
\text { auditorías, juntas de comercialización y } \\
\text { corporativizacion y racionalizacion }\end{array}$ & 3,336 \\
\hline $\begin{array}{l}\text { Políticas } \\
\text { en zonas } \\
\text { periféricas }\end{array}$ & $\begin{array}{l}\text { Problemas laborales (Sectores público y privado) } \\
\text { Límites salariales y laborales, pensiones e } \\
\text { instituciones de seguridad social }\end{array}$ & 1,991 \\
\hline
\end{tabular}




\begin{tabular}{|c|c|c|}
\hline \multirow[t]{2}{*}{$\begin{array}{l}\text { Políticas } \\
\text { en zonas } \\
\text { periféricas }\end{array}$} & $\begin{array}{l}\text { Reformas Institucionales } \\
\text { Reformas del sistema judicial, medidas } \\
\text { anticorrupción, mejora de la competencia, } \\
\text { desarrollo del sector privado, transferencia de } \\
\text { competencias, políticas sectoriales, políticas } \\
\text { sociales (excluidas las políticas de reducción de la } \\
\text { pobreza), aumentos de precios de alimentos, agua, } \\
\text { transporte público u otros bienes de necesidades } \\
\text { básicas, catastros, otorgamiento de derechos de } \\
\text { propiedad, regulaciones ambientales y acceso a } \\
\text { bienes comunes }\end{array}$ & 1,360 \\
\hline & $\begin{array}{l}\text { Políticas para la reducción de la pobreza } \\
\text { Elaboración estrategias para luchar contra la } \\
\text { pobreza, aumento del gasto del sector social e } \\
\text { implementación de redes de seguridad social }\end{array}$ & 825 \\
\hline $\begin{array}{l}\text { Número } \\
\text { total de } \\
\text { condiciones }\end{array}$ & & 58,406 \\
\hline
\end{tabular}

Fuente: Autores, realizado sobre datos disponibles en: <http://imfmonitor.org/downloads.html>.

Para investigar si la combinación de políticas de condiciones en los programas del FMI cambió, la Figura 4 muestra el porcentaje de condiciones en áreas de políticas complementarias (non-core) en los programas del FMI. Una observación inicial es que la expansión de las condicionalidades hacia las áreas no principales comenzó a mediados de la década de 1980. La proporción de condiciones en áreas no centrales alcanzó su punto máximo en 1999, fluctuó durante varios años y luego descendió marcadamente de 2005 a 2009, antes de aumentar gradualmente de nuevo. A nivel desagregado, las reformas laborales y las privatizaciones de empresas de propiedad estatal - con sus reformas asociadas- alcanzaron su punto máximo en 1999, y se han estado reduciendo desde 2006. En los últimos años también han visto un aumento en las condiciones ligadas a aspectos redistributivos, que suelen adoptar la forma de minimizar el gasto público en salud y educación. Por su parte, 
las reformas institucionales se han mantenido en los últimos años en proporciones similares a las de finales de la década de los noventa.

Figura 4. Condicionalidad en áreas periféricas, 1980-2014

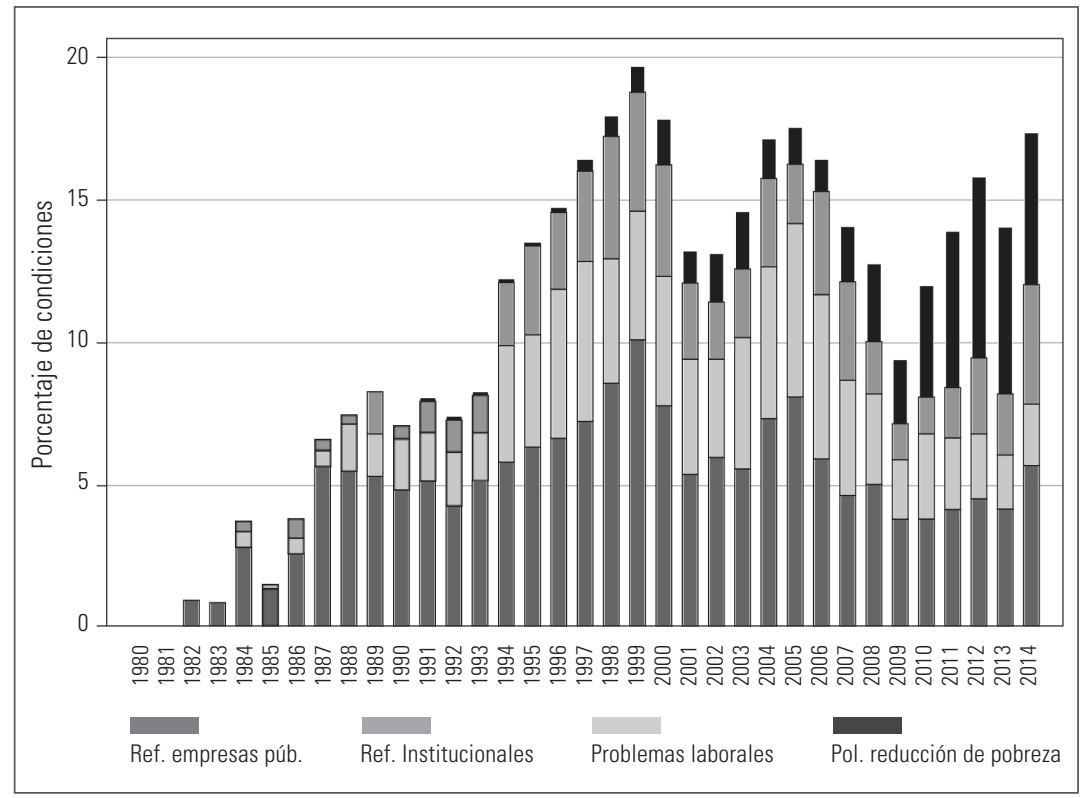

Fuente: Autores, realizado sobre datos disponibles en: <http://imfmonitor.org/downloads.html>.

En términos generales, si bien los programas del FMI no abarcan tanto como en la década de 1990, las condiciones que estipulaban reformas a las empresas estatales, a la política laboral y los entornos institucionales representaban más del $12 \%$ de todas las condiciones incluso en 2014. Lo que podría interpretarse como un alcance cada vez más limitado de las condicionalidades es explicado en parte por la cantidad de tiempo que cada país ha estado bajo los programas del FMI. ${ }^{31}$ Los países reiteradamente deudores ya han implementado un

31 Ibid. 
extenso número de condicionalidades, por lo que hay menos "necesidad" de que el FMI introduzca tales condiciones en programas recientes.

El aparato técnico de la condicionalidad también ha evolucionado con el tiempo. Los programas de préstamos del FMI emplean dos tipos de condiciones: cuantitativas y estructurales. ${ }^{32}$ Originalmente, las condiciones del FMI solo aparecían en forma de metas macroeconómicas cuantificables (por ejemplo, límites al endeudamiento del gobierno). Si bien estas condiciones cuantitativas son restrictivas, solo especifican los fines de la política en lugar de los medios, de modo que los gobiernos pueden aplicar una serie de políticas alternativas para satisfacerlas. Por el contrario, las condiciones estructurales especifican claramente los medios por los cuales se debe alcanzar el cumplimiento de las metas macroeconómicas. Por lo general, estas reformas han tenido como objetivo alterar la estructura subyacente de una economía, por ejemplo, privatizando empresas estatales, legislando la independencia del banco central, desregulando los mercados laborales o reestructurando los sistemas fiscales. La Figura 5 muestra cómo las condicionalidades estructurales comenzaron en niveles muy bajos a mediados de la década de 1980, y en el curso de una década su presencia se expandió rápidamente, alcanzando un máximo de aproximadamente el $38 \%$ de todas las condiciones a fines de la década de 1990. A partir de allí, la proporción de condicionalidades estructurales se mantuvo estable, hasta que en años recientes, volvió a expandirse. En 2014, las condiciones estructurales abarcaron el $31 \%$ de todas las condiciones. En general, estas tendencias ponen de relieve que el ajuste estructural sigue siendo tan relevante como siempre en la era contemporánea.

32 FMI, IMF Conditionality (IMF Factsheet, 2015). Disponible en http://www.imf.org/external/np/exr/facts/conditio.html 
Figura 5. Condicionalidad estructural

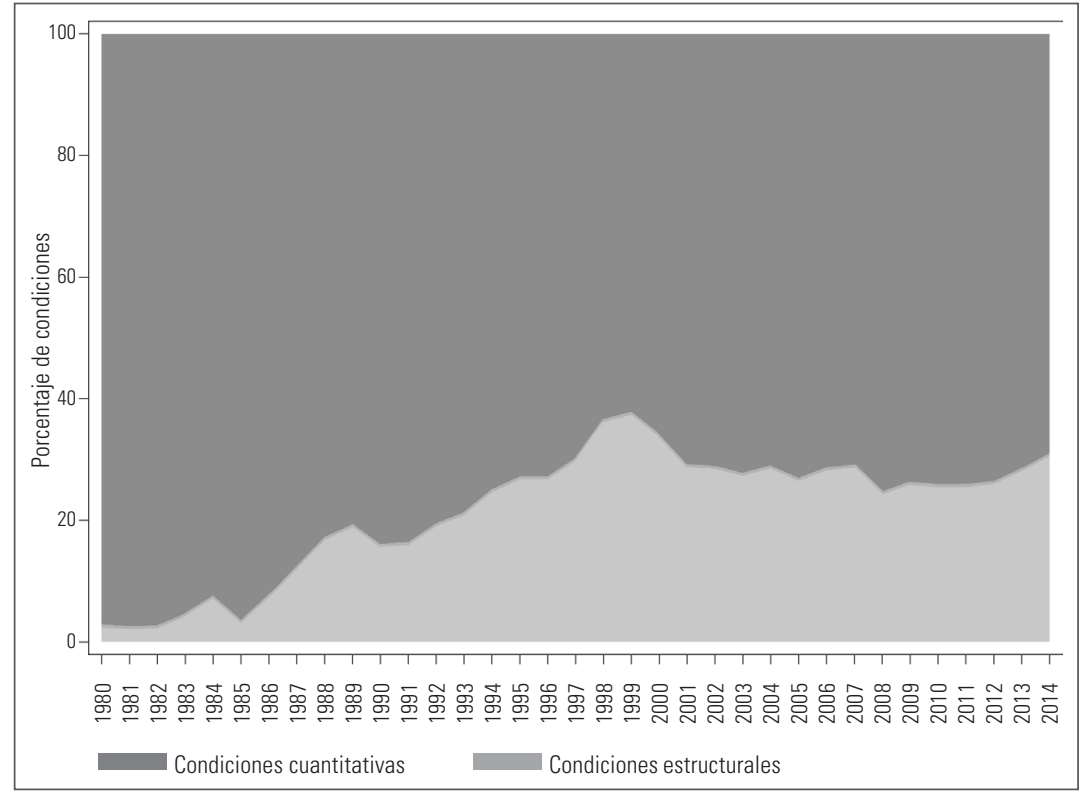

Fuente: Autores, realizado sobre datos disponibles en: <http://imfmonitor.org/downloads.html>.

\section{Los efectos de las condicionalidades sobre los derechos humanos}

En esta sección se revisan los debates existentes sobre los efectos de las condicionalidades sobre los derechos humanos, organizados en tres dimensiones temáticas: derecho a la salud, derechos laborales, y derechos civiles y políticos.

\section{IV.1. Derecho a la salud}

El derecho a la salud está codificado en el Pacto Internacional de 1966 sobre Derechos Económicos, Sociales y Culturales (PIDESC) y ampliado en la ObservaciónGgeneral 14, emitida por el Comité de Derechos Económicos, Sociales y Culturales de 
las Naciones Unidas en 2000. ${ }^{33}$ Más que una agenda minimalista que incluya intervenciones de salud para los más vulnerables, el derecho a la atención de la salud en el PIDESC forma un marco integral hacia el más alto estándar posible de salud. Ofrece una afirmación legítima de libertades y derechos directamente relacionados con la salud, incluido el acceso a una atención médica de calidad y asequible, así como los relacionados indirectamente con la salud, como el acceso a alimentos, agua, empleo y educación. ${ }^{34}$ El PIDESC y la Observación General también consagran estos derechos como obligaciones nacionales e internacionales, estas últimas relacionadas con la cooperación para el desarrollo en materia de salud. ${ }^{35}$ Aunque el FMI y el Banco Mundial han afirmado durante mucho tiempo que están preocupados por la consecuencias para la salud de sus recomendaciones de política, ${ }^{36}$ la evidencia disponible sugiere que muchas condiciones incluidas en los programas de ajuste estructural incumplen estas obligaciones y resultan perjudiciales en materia de salud.

Las condiciones del FMI y del Banco Mundial repercuten directamente en el cumplimiento del derecho a la salud de diversas maneras. ${ }^{37}$ En particular, la reducción de la pobreza, las condiciones fiscales, institucionales y laborales pueden implicar cambios rápidos en el volumen y la calidad de los servicios prestados (como instalaciones de salud y suministros médicos). Por un lado, para proteger los gastos sensibles de las medidas de austeridad, los programas de ajuste estructural incorporan condiciones de reducción de la pobreza, en la forma de pisos de

33 CESCR, "General Comment No. 14: The Right to the Highest Attainable Standard of Health (Art. 12)", UN Doc E/C.12/2000/4 (11 de agosto de 2000).

34 Gorik Ooms, Rachel Hammonds, "Global Constitutionalism, Applied to Global Health Governance: Uncovering Legitimacy Defcits and Suggesting Remedies", 12 Globalization and Health, 2016, 84.

35 Ibid.

36 Kentikelenis et al. (nota 3); Devi Sridhar, The Battle Against Hunger: Choice, Circumstance, and the World Bank (Oxford University Press, 2008).

37 Kentikelenis (nota 23). 
gasto prioritario, como es el caso de la inversión en salud y educación. ${ }^{38}$ De hecho, en la última década se visualiza un rápido aumento en la inclusión de condiciones para la reducción de la pobreza (ver Figura 4). Si bien hasta 1998 representaban menos del $1 \%$ de las condiciones anuales, desde entonces el uso de estos instrumentos ha crecido ampliamente, llegando casi al $5 \%$ de las condiciones en 2014. Estas pueden explicar parcialmente los hallazgos de estudios transversales entre países que muestran que los programas de ajuste estructural están asociados con aumentos en el gasto social en países de bajos ingresos del África subsahariana, países autocráticos y países de América Latina. ${ }^{39}$ La evidencia documental sobre los programas del FMI en países de África occidental también demuestra que, en casos específicos, los pisos de gastos prioritarios contribuyeron a aumentos en las asignaciones presupuestarias para salud, como fue el caso de Gambia en 2012 y Benín a finales de la década de $1990 .{ }^{40}$

Por otro lado, existen pruebas contundentes que sugieren que las condiciones de reducción de la pobreza reciben una importancia subsidiaria entre las condiciones fiscales. Los objetivos de gasto prioritario suelen ser condiciones no vinculantes

38 Sanjeev Gupta et al., Social Issues in IMF-Supported Programs, Occasional Paper No 191 (IMF 2000) 191; Sanjeev Gupta, “Can a Causal Link Be Drawn? A Commentary on The Impact of IMF Conditionality on Government Health Expenditure: A Cross-National Analysis of 16 West African Nations" 181 Social Science \& Medicine, 2017, 199; Sanjeev Gupta, "Response of the International Monetary Fund to Its Critics" 2 International Journal of Health Services, 2010, vol., 323; IMF, "Protecting the Most Vulnerable under IMF-Supported Programs" (IMF Factsheet, 2015). Disponible en: http://www.imf.org/external/np/exr/facts/protect.htm

39 Alexander Kentikelenis, Tomas Stubbs, Lawrence King, "Structural Adjustment and Public Spending on Health: Evidence from IMF Programs in Low-Income Countries" 126 Social Science \& Medicine, 2015, 169; Irfan Nooruddin, Joel W Simmons, "The Politics of Hard Choices: IMF Programs and Government Spending" 4 International Organization, 2006, vol. 60, 1001; Shiri Noy, "New Contexts, Diferent Patterns? A Comparative Analysis of Social Spending and Government Health Expenditure in Latin America and the OECD", 3 International Journal of Comparative Sociology, 2011, vol. 52, 215.

40 Stubbs et al.(nota 27); Tomas Stubbs et al., "The IMF and Government Health Expenditure: A Response to Sanjeev Gupta", 181 Social Science \& Medicine, 2017, 202. 
que sirven como marcadores para una evaluación más amplia del progreso, pero no suspenden automáticamente un programa si no se cumplen, mientras que los objetivos de déficit fiscal sí son vinculantes y suspenden automáticamente el préstamo. ${ }^{41}$ Además, las investigaciones muestran que los objetivos de gasto prioritario se observaron solo alrededor de la mitad de las veces, mientras que las condiciones de déficit fiscal se cumplieron casi siempre. ${ }^{42}$ Como parte de un esfuerzo de austeridad, los gobiernos pueden estar bajo presión para recortar el gasto social con el fin de cumplir con las metas de déficit fiscal, que pueden, a su vez, limitar la accesibilidad y asequibilidad de la atención médica. ${ }^{43}$

Varios estudios transversales entre países sobre los efectos del ajuste estructural en el gasto social sugieren que está asociado con disminuciones en el gasto en países de bajos ingresos fuera África subsahariana y Estados democráticos. ${ }^{44}$ Un estudio reciente centrado en los países de África occidental también encontró que cada condición adicional del FMI reduce el gasto público en salud per cápita en un $0,25 \% .{ }^{45}$ En consecuencia,

41 Tomas Stubbs, Alexander Kentikelenis, "Targeted Social Safeguards in the Age of Universal Social Protection: The IMF and Health Systems of Low-Income Countries", 2 Critical Public Health, 2018, vol. 28, 132.

42 Kentikelenis et al. (nota 3); Alexander Kentikelenis et al.,"The International Monetary Fund and the Ebola Outbreak" 2 The Lancet Global Health, 2015, vol. 3, e69; Stubbs et al. (nota 27).

43 Devi Sridhar, Ngaire Woods, "Are There Simple Conclusions on How to Channel Health Funding?" 9723 The Lancet, 2010, vol. 375, 1326; Stubbs et al. (nota 27); Aaron Reeves et al., "The Political Economy of Austerity and Healthcare: Cross-National Analysis of Expenditure Changes in 27 European Nations 1995-2011", 1 Health Policy, 2014, vol. 115, 1-8; Kentikelenis et al. (nota 1); David Stuckler, Lawrence King, Sanjay Basu, "International Monetary Fund Programs and Tuberculosis Outcomes in Post-Communist Countries", 5 PLoS Medicine, 2008, vol. 7, 1079; Pfeifer y Chapman (nota 7); Michael Tomson, Alexander Kentikelenis, Tomas Stubbs, "Structural Adjustment Programmes Adversely Afect Vulnerable Populations: A Systematic-Narrative Review of Their Efect on Child and Maternal Health" 38 Public Health Reviews, 2017.

44 Kentikelenis et al. (nota 37); Nooruddin y Simmons (nota 39).

45 Stubbs et al. (nota 25); Stubbs et al. (nota 38). 
los países experimentan escasez de suministros médicos y ven que los servicios de salud sin financiación son reemplazados por programas tradicionales ineficaces. ${ }^{46}$ Los estudios empíricos que evalúan el efecto del gasto en salud o del gasto público en general encuentran una relación significativa y perjudicial con la mortalidad infantil, mortalidad de menores de 5 años, y varios otros resultados de salud. ${ }^{47}$ El Consejo de Derechos Humanos de la ONU también informó que la disminución en el gasto público promovido por los programas del FMI en Chipre, Grecia e Irlanda se tradujo en disminuciones en el personal de atención médica, reducciones en el número de camas de hospital y mayores tiempos de espera para procedimientos médicos. ${ }^{48}$

Aparte de las condiciones fiscales que afectan el gasto público en salud, las condiciones institucionales incluidas en los programas de ajuste estructural pueden limitar la accesibilidad y asequibilidad de la atención médica. Una medida común ha sido la introducción de tarifas de usuario para acceso a la atención de la salud y la aplicación de copagos por medicamentos o servicios. ${ }^{49}$ La razón para aplicar tales tarifas era generar recursos adicionales, mejorar la eficiencia y aumentar el acceso. ${ }^{50}$ En la práctica han socavado el derecho a la salud

\footnotetext{
46 Pfeifer y Chapman (nota 9); Tomson et al. (nota 43).

47 Tomson et al. (nota 41), John C Anyanwu, Andrew EO Erhijakpor, "Health Expenditures and Health Outcomes in Africa", 2 African Development Review, 2009, vol. 21, 400; Marco A Palma-Solís et al.,"State Downsizing as a Determinants of Infant Mortality and Achievement of Millennium Development Goal 4" 39 International Journal of Health Services 389, 2009.

48 UNGA, "Report of the Independent Expert on the Efects of Foreign Debt and Other Related International Financial Obligations of States on the Full Enjoyment of All Human Rights, Particularly Economic, Social and Cultural Rights", UN Doc A/HRC/34/57/Add.1 (28 de diciembre 2016).

49 Sarah Tomson, Economic Crisis, Health Systems and Health in Europe: Impact and Implications for Policy (Open University Press 2015); Kasturi Sen, Meri Koivusalo, "Health Care Reforms and Developing Countries-A Critical Overview", 3 International Journal of Health Planning and Management, 1998, vol. 13, 199.

50 John Akin, Nancy Birdsall, David de Ferranti, Financing Health Services in Developing Countries: An Agenda for Reform (World Bank Publications, 1987).
} 
de las personas vulnerables, tanto en términos de reducir el uso de dichos servicios debido a sus costos prohibitivos, como al empobrecimiento de la población debido a los efectos de los gastos inevitables en salud. ${ }^{51}$ Un modelo de simulación de veinte países africanos que emplean tarifas de usuario para la salud concluyó que la abolición de las tarifas podría prevenir aproximadamente 233.000 muertes de menores de cinco años al año o el $6,3 \%$ de esas muertes en este entorno. ${ }^{52}$ En los últimos años, el consenso político del FMI y del Banco Mundial en torno a los países de bajos ingresos se ha alejado de la dependencia de las tarifas de los usuarios. Aún así, los recientes programas de ajuste estructural en Europa abogaban por la introducción o el aumento de tarifas de usuario o copagos, realizando rigurosos criterios de elegibilidad para los servicios de salud subsidiados. ${ }^{53}$

Las condicionalidades institucionales que exigen la desregulación del sector han fortalecido el papel del sector privado en la prestación de servicios de salud. ${ }^{54} \mathrm{Si}$ bien quienes pueden

51 Robert Yates, "Universal Health Care and the Removal of User Fees", 9680 The Lancet, 2009, vol. 373, 2078; Roberto De Vogli, Gretchen L Birbeck, "Potential Impact of Adjustment Policies on Vulnerability of Women and Children to HIV/AIDS in Sub-Saharan Africa", 2 Journal of Health, Population and Nutrition, 2005, vol. 23, 105; Chris James et al., "Impact on Child Mortality of Removing User Fees: Simulation Model", 7519 British Medical Journal, 2005, vol. 331, 747.

52 Yates, Ibid.

53 Thomson et al. (nota 43); UN Doc A/HRC/34/57/Add.1 (nota 48); M Karanikolos, A Kentikelenis, "Health Inequalities afer Austerity in Greece", 15 International Journal for Equity in Health, 2016, 83; A Kentikelenis, "Bailouts, Austerity and the Erosion of Health Coverage in Southern Europe and Ireland", 3 European Journal of Public Health, 2015, vol. 25, 365; A Kentikelenis et al.,"Health Efects of Financial Crisis: Omens of a Greek Tragedy", 9801 The Lancet, 2011, vol. 378, 1457; Alexander Kentikelenis et al.,"Greece"s Health Crisis: From Austerity to Denialism", 9918 The Lancet, 2014, vol. 383, 748; Alexander Kentikelenis et al.,"Health and the Financial Crisis in Greece-Authors" Reply", The Lancet, 2014, vol. 379, 1002; Alexander Kentikelenis et al.,"Efects of Greek Economic Crisis on Health Are Real", 345 BMJ, 2012, e8602.

54 Núria Homedes, Antonio Ugalde, "Why Neoliberal Health Reforms Have Failed in Latin America", 1 Health Policy, 2005, vol. 71, 83. 
pagar por ello obtienen acceso a un paquete más amplio de servicios, esto se combina con retrocesos impulsados por la austeridad que restringen la provisión de salud del gobierno a una gama más limitada de servicios o con la subcontratación en organizaciones no gubernamentales, que a menudo están menos equipadas para brindar servicios integrales y servicios de salud de alta calidad. ${ }^{55}$ Además, los programas de ajuste estructural están vinculados a la descentralización del sistema de salud, es decir, la transferencia de responsabilidades fiscales y operativas al nivel subnacional. ${ }^{56}$ En principio, la descentralización puede hacer que los sistemas de salud sean más sensibles a las necesidades locales, pero en la práctica a menudo crea problemas de gobernanza y exacerba las debilidades institucionales locales que socavan el derecho a la salud, especialmente a la hora de gestionar los brotes de enfermedades en todo el país. ${ }^{57}$

Las condicionalidades vinculadas a derechos laborales también pueden afectar el derecho a la salud en términos de cantidad y calidad de la fuerza laboral sanitaria disponible en el sector público, a través de despidos, congelamiento de contrataciones o recortes salariales. ${ }^{58}$ Solo en África occidental casi la mitad

\footnotetext{
55 Pfeifer y Chapman (nota 9); Rene Loewenson, "Structural Adjustment and Health Policy in Africa", 4 International Journal of Health Services, 1995, vol. 23 717; Alexander Kentikelenis, Amanda Shriwise, "International Organizations and Migrant Health in Europe", 37 Public Health Reviews, 2016, 19; Sridhar y Woods (nota 43); James Pfeifer, "International NGOs and Primary Health Care in Mozambique: The Need for a New Model of Collaboration", 4 Social Science \& Medicine, 2003, vol. 56, 725; Sundari TK Ravindran, "Privatisation in Reproductive Health Services in Pakistan: Three Case Studies", 36 Reproductive Health Matters, 2010, vol. 18, 13 .

56 Kentikelenis et al. (nota 40); Stubbs et al.(nota 27); Homedes y Ugalde (nota 52).

57 Stubbs et al. (nota 25); Kentikelenis et al. (nota 42); Mamuka Djibuti et al.,"Health Systems Barriers to Efective Use of Infectious Disease Surveillance Data in the Context of Decentralization in Georgia: A Qualitative Study", 2-3 Health Policy, 2007, vol. 83, 323.

58 Akanksha A Marphatia et al.,"Confronting the Contradictions: The IMF, Wage Bill Caps and the Case for Teachers" (Actionaid 2007); Kentikelenis et al. (nota 40); Stubbs et al. (nota 27); David Stuckler, Sanjay Basu, "The International Monetary Fund"s Efects on Global Health: Before and Afer the 2008 Financial Crisis", 4 International Journal of Health Services, 2009, vol. 39, 771; Akanksha Marphatia, "The Adverse Efects of International Monetary Fund
} 
de los años entre 1995 y 2014 que involucraron programas del FMI incluyeron condiciones que estipulaban despidos o topes en la contratación del sector público, así como límites a la masa salarial. ${ }^{59}$ Estos objetivos pueden obstaculizar la capacidad para contratar, remunerar adecuadamente o retener profesionales de la salud, y están vinculados a la "fuga de cerebros" médica, en tanto que los trabajadores de la salud pueden migrar en busca de un mejor empleo. ${ }^{60}$ El FMI informa que esos topes salariales se han descontinuado en sus programas, ${ }^{61}$ pero la evidencia reciente muestra que todavía se incorporan en algunos. ${ }^{62}$

Más allá de estos efectos directos de las condicionalidades del FMI y del Banco Mundial, el derecho a la salud también puede verse afectado indirectamente. Primero, las devaluaciones de la moneda, promovidas por el FMI y el Banco Mundial para mejorar la competitividad externa de los países, al aumentar el precio de las importaciones, impiden el acceso a medicamentos y equipos médicos importados. ${ }^{63}$ En segundo lugar, la eliminación de los derechos de aduana reduce a corto plazo los ingresos por impuestos al comercio, lo que, a menos que se sustituya por fuentes alternativas de ingresos, puede socavar la base fiscal de la política sanitaria. Sin embargo, si los beneficios económicos de la apertura estimulan el crecimiento económico en el mediano plazo o si los ingresos fiscales se recaudan por

Programs on the Health and Education Workforce", 1 International Journal of Health Services, 2010, vol. 40, 165.

59 Stubbs et al. (nota 27).

60 Karen McColl, “Fighting the Brain Drain”, 7676 British Medical Journal, 2008, vol. 337, 958; Saliwe M Kawewe, Robert Dibie, "The Impact of Economic Structural Adjustment Programs [ESAPs] on Women and Children: Implications for Social Welfare in Zimbabwe", 4 Journal of Sociology \& Social Welfare, 2000, vol. 27, 79.

61 Sanjeev Gupta, "Response to "The International Monetary Fund and the Ebola Outbreak", 3 The Lancet Global Health, 2015, vol. 2, e78.

62 Kentikelenis et al. (nota 3).

63 Jacques van der Gaag, Tania Barham, "Health and Health Expenditures in Adjusting and Non-Adjusting Countries", 8 Social Science \& Medicine, 1998, vol. 46, 995. 
otra vía (por ejemplo, a través de nuevos impuestos al consumo o por la mejora en la recaudación de impuestos), entonces se podría invertir una mayor cantidad de ingresos públicos en salud. ${ }^{64}$ En tercer lugar, la privatización de empresas de propiedad estatal (diseñada para recaudar fondos para gobiernos carentes de efectivo) puede resultar a mediano y largo plazo en pérdidas de ingresos públicos seguros para que el Estado financie la salud; y en los casos en que las empresas estatales brindaban cobertura de salud a sus empleado/as, estos beneficios pueden retirarse después de la privatización, lo que genera la pérdida del acceso a la atención médica. ${ }^{65}$ En cuarto lugar, los donantes podrían interpretar las condicionalidades como un compromiso firme con las reformas, recompensado con aumentos de la ayuda que compensarían las pérdidas de ingresos para la salud; aún así, la evidencia sugiere que la ayuda sustituye, en lugar de complementar, el gasto público en salud, y que los flujos de ayuda aumentan el presupuesto general y alivian la deuda, pero no mejoran los fondos para la salud. ${ }^{66}$

En quinto lugar, y avanzando en la cadena causal hacia los "determinantes sociales" de la salud, ${ }^{67}$ las condiciones

64 Benedict Clements, Sanjeev Gupta, Masahiro Nozaki, “What Happens to Social Spending in IMF-Supported Programmes?", 28 Applied Economics, 2013, vol. 45, 4022; Ernesto Crivelli, Sanjeev Gupta, Does Conditionality in IMF-Supported Programs Promote Revenue Reform? IMF Working Paper WP/14/206 (2014).

65 Lawrence King, Patrick Hamm, David Stuckler, "Rapid Large-Scale Privatization and Death Rates in ExCommunist Countries: An Analysis of Stress-Related and Health System Mechanisms", 3 International Journal of Health Services, 2009, vol. 39, 461; David Stuckler, Sanjay Basu, The Body Economic: Why Austerity Kills (Basic Books, 2013); David Stuckler, Lawrence King, Martin McKee, "Mass Privatisation and the Post-Communist Mortality Crisis: A Cross-National Analysis", 9661 The Lancet, 2009, vol. 373, 399; John W Peabody, "Economic Reform and Health Sector Policy: Lessons from Structural Adjustment Programs", 5 Social Science \& Medicine, 1996, vol. 43, 823.

66 Stubbs et al. (nota 17); David Stuckler, Sanjay Basu, Martin McKee, "International Monetary Fund and Aid Displacement", 1 International Journal of Health Services, 2011, vol. 41, 67; Chunling Lu et al.,"Public Financing of Health in Developing Countries: A Cross-National Systematic Analysis", 9723 The Lancet, 2010, vol. 375, 1375.

67 Michael Marmot, "Health in an Unequal World”, 9552 The Lancet, 2006, vol. 368, 2081. 
asociadas a los programas de ajuste estructural están vinculadas a la disminución de los ingresos y el aumento del desempleo, la pobreza y la desigualdad, que a su vez son las causas fundamentales de una cascada de problemas de salud a lo largo de la vida. ${ }^{68}$ Por ejemplo, los topes salariales y la privatización pueden resultar en la pérdida de puestos de trabajo, que están relacionados con el aumento del alcoholismo y el suicidio; la liberalización de las tarifas puede aumentar los precios de los alimentos, lo que está ligado al deterioro de la nutrición infantil; y la introducción de formas regresivas de impuestos puede reducir ingresos y, por lo tanto, su capacidad para financiar la atención de la salud o llevar una vida sana. ${ }^{69}$ En sexto lugar, la educación es otro determinante social clave de la salud, ya que aumenta el conocimiento de las personas sobre salud y mejora las oportunidades de movilidad social que a su vez afectan el empleo y la pobreza; sin embargo, los estudios muestran que la imposición de tarifas para la educación primaria, exigidas por el FMI y el Banco Mundial, impide que los niños y las niñas alcancen logros educativos, y que el ajuste estructural también disminuye el efecto protector de la educación de los padres sobre la salud infantil. ${ }^{70}$ Por último, las condiciones de las políticas ambientales, que suelen incluir la desregulación o privatización del agua y el saneamiento, agricultura, energía

68 James Vreeland, "The Effect of IMF Programs on Labor", 1 World Development, 2002, vol. 30, 121; Doris Oberdabernig, "Revisiting the Efects of IMF Programs on Poverty and Inequality", World Development, 2013, vol. 46, 113; Kate E. Pickett, Richard G. Wilkinson, "Income Inequality and Health: A Causal Review", Social Science \& Medicine, 2015, vol. 128, 316; UN Doc A/HRC/34/57/Add.1 (nota 48).

69 Stuckler et al. (nota 65); David Stuckler et al.,"The Public Health Efect of Economic Crises and Alternative Policy Responses in Europe: An Empirical Analysis", 9686 The Lancet, 2009, vol. 374, 315; Sudhanshu Handa, Damien King, "Adjustment with a Human Face? Evidence from Jamaica", 7 World Development, 2003, vol. 31, 1125; Frances Stewart, "The Many Faces of Adjustment", 12 World Development, 1991, vol. 19, 1847.

70 Sarah Babb, "The Social Consequences of Structural Adjustment: Recent Evidence and Current Debates", Annual Review of Sociology, 2005, vol. 31, 199; Adel Daoud et al.,"Impact of International Monetary Fund Programs on Child Health", 25 Proceedings of the National Academy of Sciences, 2017, vol 114, 6492; Kentikelenis (nota 23). 
y otros recursos naturales, están vinculadas a la degradación ambiental, que a su vez afecta la salud de la población. ${ }^{71}$

\section{IV.2. Derechos laborales}

Varios instrumentos internacionales de derechos humanos contienen disposiciones relativas al derecho laboral. El Pacto Internacional de Derechos Civiles y Políticos de 1966 (PIDCP) articula los derechos a la libertad de trabajo forzoso y la libertad de asociación, y el PIDESC encarna el derecho a participar en el trabajo y el derecho a condiciones laborales justas. Los derechos laborales también están protegidos por convenios fundamentales de la Organización Internacional del Trabajo (OIT) y la Declaración de la OIT relativa a los principios y derechos fundamentales en el trabajo de $1998 .^{72}$ En su Observación General No 18 (sobre el derecho al trabajo) de 2005, el Comité de Asuntos Económicos, Sociales y Derechos Culturales de la ONU lo entendió como el derecho de toda persona a ganarse la vida con un trabajo libremente elegido, incluido el derecho a no ser privado de trabajo injustamente. Los Estados son, por lo tanto, obligados a asignar recursos y adoptar políticas destinadas a reducir su desempleo. ${ }^{73}$ El Comité también destacó que las IFIs, como el FMI y el Banco Mundial, deben prestar atención a la protección del derecho al trabajo en sus políticas crediticias.

El FMI y el Banco Mundial han incorporado condiciones que afectan directamente el derecho al trabajo y a las condiciones

71 John Shandra, Eran Shor, Bruce London, “Debt, Structural Adjustment, and Organic Water Pollution", 1 Organization and Environment, 2008, vol. 21 38; Carrie L Shandra, John M Shandra, Bruce London, "World Bank Structural Adjustment, Water, and Sanitation: A CrossNational Analysis of Child Mortality in Sub-Saharan Africa", 2 Organization and Environment, 2011, vol. 24, 107; Pablo Pacheco, "Agricultural Expansion and Deforestation in Lowland Bolivia: The Import Substitution versus the Structural Adjustment Model" 3 Land Use Policy, 2006, vol. 23, 205.

72 ILO, ILO Declaration on Fundamental Principles and Rights at Work and Its Follow-Up (2010). 73 CESCR, "General Comment No 18: The Right to Work" UN Doc E/C.12/GC/18 (2 February 2006). 
justas de trabajo a través de la desregulación de los mercados laborales. Su fundamento se basa en observar la economía desde el lado de la oferta, postulando que las empresas invierten más cuando los mercados laborales son flexibles y cuando los costos asociados con las protecciones laborales son bajos. Por ejemplo, un informe del personal del FMI sobre Rumanía afirma que: "Las rigideces de mercado son impedimentos para un entorno de negocios favorable y Rumanía se destaca en comparación con otros países, particularmente en los costos de contratación y despido de trabajadores" ${ }^{\text {74 }}$. El FMI y el Banco Mundial consideran la fexibilidad del mercado de trabajo como un ingrediente clave para mejorar la competitividad global de los bienes y servicios producidos en los países deudores.

De todos modos, se ha criticado que el FMI y el Banco Mundial ignoran las implicaciones para los derechos humanos de reducir las rigideces del mercado laboral. ${ }^{75}$ En un informe reciente sobre programas de ajuste estructural, el Consejo de Derechos Humanos de la ONU concluye que tales políticas han contravenido obligaciones internacionales de derechos humanos al erosionar los derechos laborales. ${ }^{76}$ Un estudio que examina 131 países para el período de 1981 a 2003 halló que cuanto más tiempo estuvo sujeto un país a los programas de ajuste estructural, menor fue el nivel de protección de los derechos laborales. ${ }^{77}$ Otro estudio en 123 países encontró una asociación negativa entre los programas de ajuste estructural y los derechos laborales colectivos, en particular con respecto a la libertad

74 IMF, Romania: Staf Report for the 2006 Article IV Consultation, Country Report No. 06/168 (2006) 29.

75 Rodwan M Abouharb, David L Cingranelli, Human Rights and Structural Adjustment (Cambridge University Press, 2007); Caraway et al.(nota 26); Robert G Blanton, Shannon Lindsey Blanton, Dursun Peksen, "The Impact of IMF and World Bank Programs on Labor Rights", 2 Political Research Quarterly, 2015, vol. 68, 324; Robert G. Blanton, Dursun Peksen, “Economic Liberalisation, Market Institutions and Labour Rights", 3 European Journal of Political Research, 2016, vol. 55, 474.

76 UN Doc A/HRC/34/57/Add 1 (nota 48).

77 Abouharb y Cingranelli (nota 75). 
de asociación de los trabajadores y el derecho a la negociación colectiva, tanto en la ley como en la práctica. ${ }^{78}$

Las condicionalidades laborales han sido una característica constante de los programas de ajuste estructural desde mediados de la década de 1990, componiendo aproximadamente el $5 \%$ de todas las condiciones anuales entre 1994 y 2006, reduciéndose alrededor del $2 \%$ de todas las condiciones en 2014 (ver Figura 4). La mayoría de estas condiciones se refieren a condiciones cuantitativas relacionadas con topes salariales y límites de empleo que, a su vez, han obstaculizado el derecho al trabajo. De hecho, un estudio de 110 países encontró una asociación negativa entre los programas del FMI y los salarios de los trabajadores, aproximada a través de la participación del trabajo en el ingreso en el sector manufacturero. ${ }^{79}$ Un estudio internacional que examinó los efectos de las reformas del sector público ordenadas por el FMI encontró que los gobiernos recortan sus gastos salariales totales solo cuando esto se establece como una condición, pero se descubre evidencia de que se retorna hacia un mayor gasto en salarios una vez finalizado el programa. ${ }^{80}$ De manera similar, la participación del trabajo en relación con el producto interno bruto (PIB) disminuyó en programas de ajuste de reciente aplicación en los países de la eurozona, especialmente Grecia. ${ }^{81}$

Con respecto a los límites al empleo, las reformas laborales de Moldavia diseñadas por el FMI incluyeron medidas para "optimizar el número de empleados en el sector público", lo que significaría la eliminación de al menos 4000 puestos en $2010 .^{82}$

\footnotetext{
78 Blanton, Blanton y Peksen (nota 75).

79 Vreeland (nota 68).

80 Stephanie Rickard, Teri Caraway, "International Demands for Austerity: Examining the Impact of the IMF on the Public Sector", Review of International Organizations, 2019, vol. 14, 35. 81 George Magoulios, Dimitris Kydros, Stergios Athianos, "The Economic Crisis (2008) and Efects on Income. The Case of Greece", Procedia Economics and Finance, 2015, vol. 19, 27.

82 FMI, Republic of Moldova: Letter of Intent, Memorandum of Economic and Financial Policies, and Technical Memorandum of Understanding (IMF 2010), 7.
} 
Recientemente, se introdujeron restricciones a la contratación en el sector público en Chipre, Grecia, Irlanda y Portugal, y el programa de Túnez de 2014 incorporó el congelamiento salarial para los funcionarios públicos. ${ }^{83}$ Distintos estudios vinculan también las disposiciones incorporadas en los programas de ajuste con la disminución de las tasas de sindicalización (dado que los sindicatos son típicamente más frecuentes en el sector público), un debilitamiento del poder de negociación de los/as trabajadores/as en general, y una expansión del sector informal, reduciendo así el derecho a condiciones dignas de trabajo. ${ }^{84}$

Las condicionalidades laborales también han presentado reformas estructurales orientadas a una transformación fundamental de las instituciones de seguridad social y la desregulación de las leyes laborales. Varios estudios encuentran que el FMI y el Banco Mundial promueven leyes laborales que legalizan los contratos de trabajo temporales, extienden los períodos de prueba, eliminan las barreras para los despidos, reducen los derechos de los empleados y desmantelan los derechos de formar y afiliarse a sindicatos y de negociar colectivamente con los empleados. ${ }^{85}$ Enfatizando la ubicuidad de tales medidas, una investigación encontró que casi un tercio de las cartas de intención entre el FMI y los gobiernos en el período 1998-2005

\footnotetext{
83 Ver UN Doc A/HRC/34/57/Add.1 (nota 48).

84 Nathan Martin, David Brady, "Workers of the Less Developed World Unite? A Multilevel Analysis of Unionization in Less Developed Countries", 4 American Sociological Review, 2007, vol. 72, 562; Vreeland (nota 68); ver UN Doc A/HRC/34/57 (27 de diciembre de 2016) "Report of the Independent Expert on the Efects of Foreign Debt and Other Related International Financial Obligations of States on the Full Enjoyment of All Human Rights, Particularly Economic, Social and Cultural Rights"; Kenneth Roberts, "Social Inequalities without Class Cleavages in Latin America's Neoliberal Era", Studies in Comparative International Development, 2002, vol. 36, 3.

85 Caraway et al.(nota 27); Abouharb y Cingranelli (nota 75); Blanton, Blanton y Peksen (nota 75); UN Doc A/HRC/ 34/57 (nota 84); Katrina Burgess, "Global Pressures, National Policies, and Labor Rights in Latin America", Studies in Comparative International Development, 2010, vol. 45, 198; Peter Bakvis, "The World Bank"s Doing Business Report: A Last Fling for the Washington Consensus?", 3-4 Transfer: European Review of Labour and Research, 2009, vol. 15,419 .
} 
contenían compromisos para una flexibilización en la regulación del mercado laboral. ${ }^{86}$

Los ejemplos de este tipo abundan. En una solicitud de asistencia financiera de Marruecos en 2011, el FMI hizo hincapié en la necesidad de desregular los contratos de duración determinada y reducir las protecciones estatutarias del trabajo. ${ }^{87} \mathrm{El}$ programa del FMI para Rumanía en 2010 se centró en un recorte del $15 \%$ de las pensiones y una condición que estipulaba la aprobación parlamentaria de una reforma de la legislación del sistema de pensiones, que incluía nuevas reducciones en los pagos y aumentos en la edad de jubilación. ${ }^{88}$ Los programas recientes del FMI en los países europeos también incorporaron reformas laborales sobre la desregulación y sistemas de seguridad social. El programa de Grecia incluía reformas al sistema de negociación colectiva, la prioridad de los acuerdos a nivel de empresa (en contraposición a los sectoriales) y la reducción de los salarios mínimos y los costos de despido de empleados. ${ }^{89}$ De manera similar, el programa de ajuste de Portugal estipulaba aumentos en la edad de jubilación, el debilitamiento de la negociación colectiva y la introducción de una ley laboral de la administración pública destinada a alinear el régimen de empleo público con las reglas del sector privado y poner fin a la estabilidad del empleo público. ${ }^{90}$ Más aún, la mayoría de los gobiernos latinoamericanos han realizado cambios en sus leyes que rigen la contratación, el despido y las horas de trabajo en los últimos veinte años como resultado de la presión del FMI. ${ }^{91}$

\footnotetext{
86 Mark Anner, Teri Caraway, "International Institutions and Workers" Rights: Between Labor Standards and Market Flexibility", Studies in Comparative International Development, 2010, vol. 45, 151

87 UN Doc A/HRC/34/57 (nota 84).

88 Kentikelenis et al. (nota 3).

89 Ibid; Alexander Kentikelenis, "The Social Afermath of Economic Disaster: Karl Polanyi, Countermovements in Action, and the Greek Crisis", 1 Socio-Economic Review, 2018, vol. 16, 39.

90 Kentikelenis et al. (nota 3).

91 Burgess (nota 85).
} 
Las condicionalidades de privatización, reforma y fijación de precios de las empresas estatales también pueden obstaculizar el derecho al trabajo. Para el FMI y el Banco Mundial, las empresas estatales han sido consideradas como la principal fuente de déficit público que, a su vez, inducen muchos de los problemas económicos que hacen que los países recurran a estas instituciones en busca de préstamos. ${ }^{92}$ Lógicamente, han pedido reformas de gran alcance en las empresas estatales con el fin de reducir ayudas y limitar el déficit en el presupuesto nacional. Estas condiciones suelen socavar los derechos laborales al exigir reducciones en los derechos de los/as empleados/as en las empresas estatales; también pueden afectar los derechos laborales colectivos como daño colateral del poder de negociación decreciente de la fuerza de trabajo, dado que el sector de las empresas estatales presenta típicamente altos niveles de representación colectiva. Por ejemplo, en un programa del FMI de 1993, Mongolia acordó "establecer nuevos procedimientos de gobierno empresarial" para sus empresas de propiedad estatal, "incluidos los requisitos de rendimiento a plazos fijos de los contratos de gestión". ${ }^{33}$ En Pakistán, la privatización de empresas estatales condujo a la sustitución de trabajos estables por trabajos precarios mediante subcontratistas, que no quedan totalmente sujetos a las disposiciones de la legislación laboral. ${ }^{94}$

Finalmente, varias condiciones pueden afectar indirectamente la protección de los derechos laborales. Aquellas relacionadas con el comercio y el sistema cambiario exigen con frecuencia la liberalización del comercio, que provoca una

\footnotetext{
92 John Waterbury, "The Heart of the Matter? Public Enterprise and the Adjustment Process" en Stephan Haggard y Robert Kaufman (eds.), The Politics of Economic Adjustment: International Constraints, Distributive Conficts and the State (Princeton University Press, 1992, 182.

93 FMI, Mongolia: Staf Report for the 1993 Article IV Consultation and Request for Arrangements under the Enhanced Structural Adjustment Facility. Doc EBS/93/79 (IMF 1993), 62.

94 Kamal A Munir, Natalya Naqvi, Adaner Usmani, "The Abject Condition of Labor in Pakistan", International Labor and Working-Class History, 2015, vol. 87, 174.
} 
carrera a la baja con respecto a los derechos laborales, ya que los productores nacionales presionan a los responsables de la formulación de políticas para reducir los costos laborales a fin de resistir la competencia global. ${ }^{95}$ Además, las condiciones del sector fnanciero que imponen una política monetaria restrictiva pueden convencer a los hacedores de políticas de eliminar derechos de los trabajadores, como el salario mínimo, ya que los niveles salariales más altos tienden a ser inflacionarios. ${ }^{96}$

\section{IV.3. Derechos civiles y políticos}

La responsabilidad del Estado con respecto a los derechos civiles y políticos está codificada en el PIDCP. Los derechos políticos se refieren al derecho al voto, el derecho a la libertad de expresión y de prensa, y el derecho a no ser discriminado por motivos de origen étnico, género, orientación sexual, idioma, religión, clase social u opinión política. Los derechos civiles, también conocidos como derechos de integridad personal o integridad física, denotan el derecho a ser protegido contra la tortura, ejecuciones extrajudiciales, desapariciones o encarcelamientos políticos, entre otros. ${ }^{97}$ Si bien existen menos investigaciones sobre los efectos de las condiciones de ajuste estructural sobre los derechos civiles y políticos que sobre los derechos laborales y a la salud, la mayoría de los estudios coinciden en que la imposición de estas políticas exacerba las violaciones de estos derechos humanos. A diferencia del

\footnotetext{
95 Layna Mosley, Saika Uno, "Racing to the Bottom or Climbing to the Top? Economic Globalization and Collective Labor Rights", 8 Comparative Political Studies, 2007, Vol. 40, 923; Robert G Blanton, Shannon Lindsey Blanton, Dursun Peksen, "Financial Crises and Labor: Does Tight Money Loosen Labor Rights?", World Development, 2015, vol. 76, 1; Blanton, Blanton y Peksen (nota 75); Abouharb y Cingranelli (nota 75); Martin y Brady (nota 84); Blanton, Blanton y Peksen (nota 73); Nita Rudra, Globalization and the Race to the Bottom in Developing Countries: Who Really Gets Hurt? (Cambridge University Press, 2008).

96 Blanton, Blanton y Peksen (nota 75).

97 Abouharb y Cingranelli (nota 75).
} 
derecho a la salud y los derechos laborales, no es posible aislar las condiciones específicas que afectan a los derechos civiles y políticos; más bien, el efecto está mediado por una serie de condicionalidades sobre áreas de políticas públicas vinculadas a liberalización y ajuste. ${ }^{98}$

Los argumentos que relacionan los programas de ajuste estructural con las violaciones de los derechos civiles y políticos se basan en dos vínculos causales. Primero, una vía directa sugiere que la transferencia de poder del Estado al mercado debida a las condicionalidades puede provocar mayores abusos de derechos, ya que se debilita la capacidad del gobierno para hacer cumplir esos derechos. ${ }^{99}$ La protección de los derechos civiles, por ejemplo, requiere de gastos gubernamentales para tener jueces/juezas, policías y militares debidamente capacitados y adecuadamente remunerados, y para tener instituciones que monitoreen las actividades de estas últimas entidades de aplicación de la ley. ${ }^{100}$ Un estudio reciente también ha demostrado que los programas del FMI están asociados al deterioro de los niveles de respeto por los derechos de la mujer porque socavan la capacidad de los gobiernos y voluntad de proteger tales derechos. ${ }^{101}$ Adicionalmente, los estudios transversales entre países encuentran evidencia de que la participación en programas de ajuste estructural está asociada con reducciones

98 Rodwan M. Abouharb, David L. Cingranelli, “The Human Rights Efects of World Bank Structural Adjustment, 1981-2000", 2 International Studies Quarterly, 2006, Vol. 50, 233; Rodwan M. Abouharb, David L. Cingranelli, "IMF Programs and Human Rights, 1981-2003", Review of International Organizations, 2009, vol. 4, 47.

99 Nicole Detraz, Dursun Peksen, "The Efect of IMF Programs on Women's Economic and Political Rights", 1 International Interactions, 2016, vol. 42, 81; Abouharb y Cingranelli (nota 75); Abouharb y Cingranelli, "The Human Rights Efects of World Bank Structural Adjustment, 1981-2000" (nota 98); Abouharb y Cingranelli, "IMF Programs and Human Rights, 1981-2003" (nota 96); Jack Donnelly, Universal Human Rights in Theory and Practice (3rd edn, Cornell University Press 2013); Neil A Englehart, "State Capacity, State Failure, and Human Rights", 2 Journal of Peace Research, 2009, vol. 46, 163.

100 Abouharb y Cingranelli, "IMF Programs and Human Rights, 1981-2003" (nota 99).

101 Detraz y Peksen (nota 97). 
en los niveles de democracia de los países deudores. ${ }^{102}$ Sin embargo, otras investigaciones recientes contradicen estos estudios, observando un efecto modesto pero positivo de la participación en los programas del FMI sobre la democracia. ${ }^{103}$ El referido trabajo sostiene que los regímenes autocráticos tienen menos capacidad para reprimir la oposición cuando están bajo una restricción presupuestaria más estricta impuesta por el FMI, lo que permite que surjan mayores niveles de competencia política. Otro estudio sobre 131 países en desarrollo entre 1981 y 2003 muestra que, si bien los programas de ajuste estructural llevaron a mayores dificultades para las personas pobres, mayor conflicto civil y más represión de los derechos humanos, también están — paradójicamente- asociados con algunas reformas democráticas, incluidas elecciones más libres y justas, mayor libertad para formar y unirse a organizaciones, y una mayor libertad de expresión y de prensa. ${ }^{104}$

En segundo lugar, una vía indirecta sugiere que la vulneración de los derechos laborales y a la salud que conllevan las condicionalidades da como resultado un aumento de la protesta social y la inestabilidad, llevando a que el gobierno de turno utilice la represión violenta, lo que supone el incumplimiento de los derechos civiles y políticos. Conocemos varios estudios que prueban y apoyan esta relación causal agregada. ${ }^{105}$ La secuencia de eventos en Bolivia ejemplifica este argumento. ${ }^{106}$ Los

102 Robert Barro, Jong-Wha Lee, "IMF Programs: Who Is Chosen and What Are the Efects?", 7 Journal of Monetary Economics, 2005, vol. 52, 1245; Chelsea Brown, "Democracy's Friend or Foe? The Efects of Recent IMF Conditional Lending in Latin America", 4 International Political Science Review, 2009, vol. 30, 431.

103 Stephen Nelson, Geofrey PR Wallace, "Are IMF Lending Programs Good or Bad for Democracy?", 4 Review of International Organizations, 2017, vol. 12, 523.

104 Abouharb y Cingranelli (nota 76).

105 Ibid; Abouharb y Cingranelli, "The Human Rights Efects of World Bank Structural Adjustment, 1981-2000" (nota 99); Abouharb y Cingranelli, "IMF Programs and Human Rights, 1981-2003" (nota 99); James Franklin, "IMF Conditionality, Threat Perception, and Political Repression: A Cross-National Analysis", 5 Comparative Political Studies, 1997, vol. 30, 576.

106 Abouharb y Cingranelli (nota 74). 
limitados progresos alcanzados durante un período de 15 años de sucesivos programas de ajuste estructural llegaron a un punto crítico a principios de la década de 2000. Tras el aumento del desempleo y la pobreza, se redujeron los salarios, hubo recortes en los gastos sociales y - lo más infame- la privatización del servicio de aguas y cloacas de Cochabamba, con sus consecuentes subidas de precios. Los más afectados respondieron con una serie de manifestaciones y protestas contra el gobierno, a las que éste respondió declarando el estado de emergencia y aumentando el uso de la fuerza contra los manifestantes.

Ya hemos descrito cómo las poblaciones enfrentan aumentos en el desempleo, la pobreza y la desigualdad bajo los programas de ajuste estructural debido a las condicionalidades sobre los topes salariales, despidos y eliminación de controles de precios y subsidios para productos básicos. Varios estudios han documentado también cómo las dificultades causadas por estas políticas conducen a protestas y conflictos, y varios episodios ilustran este punto. ${ }^{107}$ En Turquía, por ejemplo, surgió un amplio malestar social tras el anuncio de que el gobierno elegido democráticamente había firmado un programa del FMI en junio de 1980 y, para septiembre de ese año, los militares habían disuelto el parlamento y suspendido las instituciones políticas civiles. ${ }^{108}$ Los estudios empíricos transversales entre naciones también apoyan la hipótesis de que los programas de ajuste estructural están asociados con aumentos en la inestabilidad social y política, incluidos incidentes

107 John Walton, David Seddon, Free Markets and Food Riots: The Politics of Global Adjustment (Blackwell, 1994); Andy Storey, “Economics and Ethnic Confict: Structural Adjustment in Rwanda", 1 Development Policy Review, 1999, vol. 17, 43; Regine Andersen, "How Multilateral Development Assistance Triggered the Confict in Rwanda", 3 Tird World Quarterly, 2000, vol. 21, 441; Javier Auyero, "Glocal Riots", 1 International Sociology, 2001, vol. 16, 33; Christian Morrisson, Jean-Dominique Lafay, Sebastien Dessus, "The Political Conditions of Adjustment in Africa 1980-90" en Rolph van der Hoeven y Fred Van der Kraaij (eds.), Structural Adjustment and Beyond in Sub-Saharan Africa: Research and Policy Issues (Heinemann, 1994), 126.

108 Nelson y Wallace (nota 103), 523. 
en manifestaciones masivas, huelgas, disturbios, confictos y golpes de Estado. ${ }^{109}$ Finalmente, los programas de ajuste estructural están vinculados a la disminución del crecimiento económico, ${ }^{110}$ que a su vez se asocian con una reducción del respeto a los derechos humanos. ${ }^{111}$

\section{IV.4. Caminos a seguir}

Al ofrecer préstamos a cambio de reformas de políticas públicas, el FMI y el Banco Mundial tienen una influencia política sustancial sobre los gobiernos de todo el mundo. Hemos demostrado que, desde la introducción del ajuste estructural en la década de 1980, las dos organizaciones han realizado continuos intentos de reformar las instituciones subyacentes de los países prestatarios, particularmente mediante condicionalidades de ajuste, liberalización, desregulación y privatización. Al profundizar en el contenido exacto de las políticas contenidas en estos programas, nuestra descripción general reveló

109 Caroline A. Hartzell, Matthew Hoddie, Molly Bauer, "Economic Liberalization via IMF Structural Adjustment: Sowing the Seeds of Civil War?", 2 International Organization, 2010, vol. 64, 339; Brett A Casper, "IMF Programs and the Risk of a Coup D'etat", 5 Journal of Confict Resolution, 2017, vol. 61, 964; John Walton, Charles Ragin, "Global and National Sources of Political Protest: Third World Responses to the Debt Crisis", 6 American Sociological Review, 1990, vol. 55, 876; Juha y Auvinen, "IMF Intervention and Political Protest in the Third World: A Conventional Wisdom Refned", 3 Third World Quarterly, 1996, vol. 17, 377; Axel Dreher, Martin Gassebner, "Do IMF and World Bank Programs Induce Government Crises? An Empirical Analysis", 2 International Organization, 2012, vol. 66, 329.

110 Barro y Lee (nota 102); Axel Dreher, "IMF and Economic Growth: The Efects of Programs, Loans, and Compliance with Conditionality", 5 World Development, 2006, vol. 34, 769; Adam Przeworski, James Vreeland, "The Efect of IMF Programs on Economic Growth", Journal of Development Economics, 2000, vol. 62, 385; James Vreeland, The IMF and Economic Development (Cambridge University Press, 2003).

111 Abouharb y Cingranelli (nota 76); Christian Davenport, David A. Armstrong, “Democracy and the Violation of Human Rights: A Statistical Analysis from 1976 to 1996", 3 American Journal of Political Science, 2004 vol. 48, 538; Steven C. Poe, C. Neal Tate, "Repression of Human Rights to Personal Integrity in the 1980s: A Global Analysis", 4 American Political Science Review, 1994, vol. 88, 853; Steven C. Poe, C. Neal Tate, Linda Camp Keith, "Repression of the Human Right to Personal Integrity Revisited: A Global Cross-National Study Covering the Years 1976-1993", 2 International Studies Quarterly, 1999, vol. 43, 291 
que las condicionalidades tienen implicaciones mayormente perversas sobre los derechos a la salud, laborales y derechos civiles y políticos.

En 2001, respondiendo a las críticas de que las IFIs estaban ignorando las consecuencias sobre los derechos humanos de sus propias actividades, un portavoz del FMI declaró que no tenían un mandato para promover los derechos humanos y que no estaban "obligados por las diversas declaraciones y convenciones de derechos humanos". ${ }^{112}$ De hecho, parece que todas estas organizaciones tratan de evitar el lenguaje de los derechos humanos. Según un redactor de discursos de la ex directora gerente del FMI Christine Lagarde, "No se pueden poner los derechos humanos en un discurso, [o] serán eliminados". ${ }^{113}$ Pero con la memoria reciente de la graves violaciones de los derechos humanos de los programas de ajuste estructural de Grecia, ${ }^{114}$ el Comité de Derechos Económicos, Sociales y Culturales emitió una declaración expresando que las IFIs están "obligadas a respetar los derechos humanos que forman parte del derecho internacional consuetudinario o de los principios generales del derecho, los cuales son fuentes de derecho internacional". ${ }^{115}$ Dado que es una responsabilidad legal del FMI y el Banco Mundial defender los derechos humanos, ${ }^{116}$ queda la pregunta de cómo las prácticas crediticias de estos organismos podrían renovarse de manera que se aseguren de hacerlo.

112 Gustavo Capdevila, "IMF Not Taking into Account Human Rights Issues" (Global Policy Forum, 13 de agosto de 2001). Disponible en: https://www.globalpolicy.org/component/ content/article/209/42944.html

113 Teresa Reinold, “The Path of Least Resistance: Mainstreaming 'Social Issues' in the International Monetary Fund", 3 Global Society, 2017, vol 31, 392.

114 Olivier de Schutter, Paul Dermine, The Two Constitutions of Europe: Integrating Social Rights in the New Economic Architecture of the Union (2016) CRIDHO Working Paper.

115 CESCR, Public Debt, Austerity Measures and the International Covenant on Economic, Social and Cultural Rights, UN Doc E/C.12/2016/1 (24 de junio de 2016).

116 Para un panorama de la compleja problemática de las obligaciones para con los derechos humanos que poseen las IFI, Ilias Bantekas, Lutz Oette, International Human Rights Law and Practice (2da ed., Cambridge University Press, 2016), cap. 18. 
De cara al futuro, los mecanismos identificados en este panorama deberían servir como guía para recalibrar los programas de ajuste estructural de manera que protejan y respeten los derechos humanos. En particular, los programas futuros deberían diseñarse bajo la consideración central de los derechos humanos. Esto implica un cambio de la gestión de los efectos negativos sobre los derechos humanos causados por las condicionalidades (por ejemplo, a través de los pobremente ejecutados objetivos sociales y de gasto prioritario) a evitar políticas que pongan en riesgo tales derechos. Como corolario, se debería realizar una evaluación de impacto sobre los derechos humanos antes de comenzar un programa, debiendo involucrar una consulta con las partes interesadas pertinentes, incluidos expertos en salud pública, sindicatos, OIT y el Consejo de Derechos Humanos de la ONU. Los programas también deberían revisarse periódicamente y ser evaluados no solo en relación con sus objetivos económicos y fiscales, sino también con respecto a sus objetivos de política social, incluida la reducción del desempleo, la pobreza y la exclusión social, y en términos de mayor acceso a una atención médica asequible. Un principio fundamental de las organizaciones del sistema de las Naciones Unidas, como las IFIs, es no causar daño. Es hora de que esta prescripción se tome en serio ${ }^{117}$.

117 Este artículo se basa en Thomas Stubbs y Alexander Kentikelenis, "International Financial Institutions and Human Rights: Implications for Public Health", 38 Public Health Reviews, 2017, 27. 